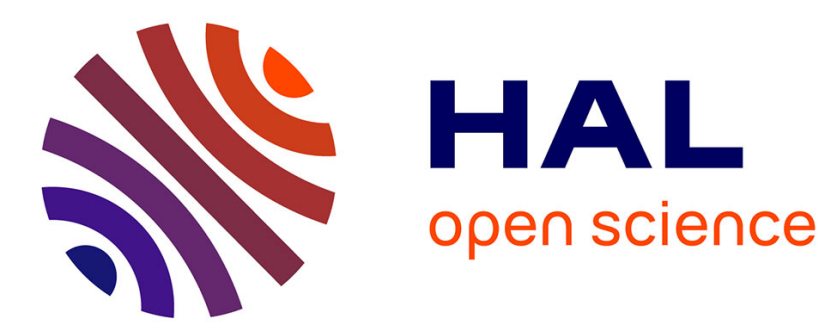

\title{
Impact of aerosols present in Titan's atmosphere on the CASSINI radar experiment
}

S. Rodriguez, Philippe Paillou, M. Dobrijevic, G. Ruffié, P. Coll, J. M. Bernard, P. Encrenaz

\section{- To cite this version:}

S. Rodriguez, Philippe Paillou, M. Dobrijevic, G. Ruffié, P. Coll, et al.. Impact of aerosols present in Titan's atmosphere on the CASSINI radar experiment. Icarus, 2003, 164, pp.213-227. 10.1016/S00191035(03)00125-8 . hal-00399910

\section{HAL Id: hal-00399910 \\ https://hal.science/hal-00399910}

Submitted on 1 Jul 2009

HAL is a multi-disciplinary open access archive for the deposit and dissemination of scientific research documents, whether they are published or not. The documents may come from teaching and research institutions in France or abroad, or from public or private research centers.
L'archive ouverte pluridisciplinaire HAL, est destinée au dépôt et à la diffusion de documents scientifiques de niveau recherche, publiés ou non, émanant des établissements d'enseignement et de recherche français ou étrangers, des laboratoires publics ou privés. 


\section{Impact of aerosols present in Titan's atmosphere on the CASSINI radar experiment}

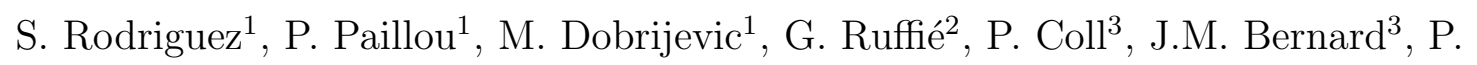
Encrenaz ${ }^{4}$

E-mail: rodriguez@obs.u-bordeaux1.fr

${ }^{1}$ OASU-L3AB UMR 5804, BP 89, 33270 Floirac, France ${ }^{2}$ ENSCPB-PIOM, Université Bordeaux I, 33400 Talence, France ${ }^{3}$ LISA, UMR 7583, Université Paris 12, 94010 Créteil, France ${ }^{4}$ LERMA, UMR 8540, Observatoire de Paris, 75014 Paris, France

Submitted to Icarus (journal)

Submitted 09/10/2002 (date)

Revised (date)

Manuscript Pages: 43

Tables: 5

Figures: 7 
Proposed Running Head: Impact of Titan's atmosphere on the Cassini radar

\section{Editorial correspondence to:}

Sébastien Rodriguez

Laboratoire d'Astrodynamique, d'Astrophysique et d'Aéronomie de Bordeaux

2 , rue de l'Observatoire

B.P. 89

33270 Floirac, France.

Phone: 33-5-57-77-61-19

Fax: 33-5-57-77-61-55

E-mail: rodriguez@obs.u-bordeaux1.fr 


\section{ABSTRACT}

Simulations of Titan's atmospheric transmission and surface reflectivity have been developed in order to estimate how Titan's atmosphere and surface properties could affect performances of the Cassini radar experiment. In this paper we present a selection of models for Titan's haze, vertical rain distribution, and surface composition implemented in our simulations. We collected dielectric constant values for the Cassini radar wavelength $(\sim 2.2 \mathrm{~cm})$ for materials of interest for Titan: liquid methane, liquid mixture of methane-ethane, water ice and light hydrocarbon ices. Due to the lack of permittivity values for Titan's haze particles in the microwave range, we performed dielectric constant $\left(\varepsilon_{r}\right)$ measurements around $2.2 \mathrm{~cm}$ on tholins synthesized in laboratory. We obtained a real part of $\varepsilon_{r}$ in the range of $2-2.5$ and a loss tangent between $10^{-3}$ and $5 \cdot 10^{-2}$. By combining aerosol distribution models (with hypothetical condensation at low altitudes) to surface models, we find the following results: (1) Aerosol-only atmospheres should cause no loss and are essentially transparent for Cassini radar, as expected by former analysis. (2) However, if clouds are present, some atmospheric models generate significant attenuation that can reach $-50 \mathrm{~dB}$, well below the sensitivity threshold of the receiver. In such cases, a $13.78 \mathrm{GHz}$ radar would not be able to measure echoes coming from the surface. We thus warn about possible risks of misinterpretation if a "wet atmosphere" is not taken into account. (3) Rough surface scattering leads to a typical response of $\sim-17 d B$. These results will have important implications on future Cassini radar data analysis.

Key words: Titan; satellites, atmospheres; surfaces, satellite; radar 


\section{Introduction}

Titan is the second largest satellite in the solar system. It is the only one known to possess an extended and dense atmosphere, hiding its surface. Primarily composed of $\mathrm{N}_{2}$ with less than $10 \% \mathrm{CH}_{4}$ and $1 \% \mathrm{H}_{2}$, Titan's thick atmosphere is subject to an active chemistry induced by solar insolation, solar wind and charged particles from the saturnian magnetosphere. This chemistry results in the production of a great diversity of hydrocarbons and nitriles in the stratosphere with increasing complexity and molecular weight (Yung et al. 1984; Toublanc et al. 1995; Lara et al. 1996; 1998). Settling in the atmosphere, chemistry end products form an extensive system of organic aerosol haze responsible for Titan's characteristic orange color and hiding the lower atmosphere and the surface at UV-visible-NIR wavelengths. It is also possible that lighter hydrocarbons or nitriles diffuse downwards and condense as liquids or solids on aerosols below altitudes of $85 \mathrm{~km}$.

Ground-based observations, as well as Pioneer and Voyager missions, have brought a great number of constraints on the haze properties but revealed the difficulty to precisely determine not only its horizontal and vertical structure but also its chemical composition. Concerning the surface, radar observations and microwave radiometry or near-infrared studies only reveal the presence of a heterogeneous surface plausibly composed of randomly distributed patches of water ice and organic compounds, solid or liquid (Muhleman et al. 1990; Coustenis et al. 1995; 1997; 2001). The precise nature of Titan's surface is still completely unknown. With the hope of disclosing the remaining questions about its composition, the CASSINI-HUYGENS spacecraft - a joint NASA/ESA/ASI mission - was launched in 1997 and will reach Saturn in 2004. The 
spacecraft, composed of an orbiter and a probe, will favour the exploration of Titan. A multipurpose radar was included in the scientific payload of the Cassini orbiter. Three active modes (SAR - for Synthetic Aperture Radar -, altimeter and scatterometer) and one passive mode (radiometer) will be used within the Radar experiment. Thanks to its active modes, the Radar instrument is expected to be able to observe Titan's surface through its dense atmosphere and thus determine whether oceans are present and map the geology and the topography of the solid surface of Titan.

These scientific goals rely on analysis of the received radar echoes and the analysis depends on models describing microwave transmission in the atmosphere and on surface reflectivity. In this paper, we present a quantitative study of the possible impact of particles present in Titan's atmosphere on the Cassini Radar experiment and some results about surface reflectivity. We first present the models of Titan's surface and atmosphere we selected as a basis for our computations. Then, in section 3 we show results of experiments designed to determine the electromagnetic properties of titanian aerosol analogs - called tholins. We finally discuss in section 1 the possible behaviour of the Cassini Radar in presence of atmospheric haze and rain on the basis of simple simulation of radar wave propagation for various models for aerosol and rain particles formation. We also show some simulations of the backscattered power by smooth and rough surfaces covered with tholins. 


\section{Distribution of condensates in Titan's atmosphere and on its surface}

\subsection{Meso- and stratosphere: vertical distribution of aerosol haze}

Since 1973, there is observational evidence for the existence of an aerosol component in Titan's upper atmosphere. Particles with size greater than molecules were invoked to reconcile models of Titan's upper atmosphere and polarimetric and photometric observations (Veverka 1973; Zellnen 1973; Rages and Pollack 1980). Several radiative transfer models incorporating aerosols were published, considering the shape and optical properties of these aerosols as free parameters, as well as their vertical distribution in terms of size and number density. These models were regularly adjusted to be consistent with the growing number of observational data of increasing resolution. First generation models (Danielson et al. 1973; Podolak and Danielson 1977) assumed a homogeneous atmosphere where dust particles and gas were uniformly mixed above the surface of Titan. Podolak and Given (1979), Rages and Pollack (1980), Tomasko (1980), and Rages and Pollack (1983) used in their calculations multi-layer models and Tomasko and Smith (1982) used the first totally inhomogeneous models with a gradient in particle size with the optical depth. They constrained the aerosol mean radius to between $0.1 \mu \mathrm{m}$ and $0.5 \mu \mathrm{m}$, but always failed to simultaneously fit the polarimetric and photometric data acquired by Pioneer and Voyager missions when considering spherical particles of single size mode.

Further studies greatly improved the model fit to data with the use of more complex haze distribution models. Inspired by the pioneer work of Toon et al. (1980), 
McKay et al. (1989) considered Titan's aerosols properties in the new light of microphysical modeling, with the aim of integrating these results in a radiative-convective model of the thermal structure of Titan's atmosphere. They assumed that all particles at a fixed altitude had the same radius and that only thermal coagulation, sedimentation, and electrostatic forces are responsible for variations in particle size and concentration with altitude. They predicted a size of $\sim 0.4 \mu \mathrm{m}$ for the aerosols around an altitude of $85 \mathrm{~km}$, in good agreement with previous values obtained from observational fits. In the same way, Cabane et al. (1992) developed a model including sedimentation and eddy diffusion accounting for transport processes, gravitational (coalescence) and thermal coagulation for collection processes. Their calculations focused on the prediction of the distribution and radius of aerosol particles throughout the atmosphere between the higher formation region and the lower stratosphere (above $85 \mathrm{~km}$ ), before condensation of hydrocarbons and nitriles on the aerosols could occur. The final particle radius obtained in the low stratosphere is about $0.2 \mu \mathrm{m}$. In the meantime, Frère et al. (1990) pursued the development of a complete microphysical modeling of Titan's aerosols, including for the first time condensation processes of organics and nitriles present in the gas phase in the low stratosphere. Above $100 \mathrm{~km}$, the profiles computed by McKay et al. (1989), Frère et al. (1990), and Cabane et al. (1992) are quite similar. The recent microphysical modeling taking into account aerosol growth into fractal aggregates (Rannou et al. 1993; Cabane et al. 1993; Rannou et al. 1995) gives concentrations and effective profiles (Fig. 1 and 3 in Cabane et al. (1993)) close to those given by classical microphysics dealing with spherical particles (close enough for the precision in radius and concentration we need), so we will not consider this model here. Besides in the wavelengths range we consider, fractal nature of micron-sized scatter- 
ers would not have significant effect on scattering and absorption calculations. Figure 1 - (a) shows profiles of aerosol radius and concentration versus altitude resulting from computation by McKay et al. (1989), Frère et al. (1990) and Cabane et al. (1992).

\subsection{Low stratosphere and troposphere: models for clouds and rain}

After a rapid lapse rate below $120 \mathrm{~km}$ altitude, the thermal profile of Titan reaches a minimum of $74 \mathrm{~K}$ at the tropopause $(42 \mathrm{~km})$. This thermodynamical cold trap region certainly induces saturation (even supersaturation for the dominant and more volatile species) and probably gas/liquid or solid phase transitions. These transitions should occur for most of the organics and nitriles present in gas phase if seed nuclei are present (Sagan and Thompson 1984; Frère et al. 1990). If nucleation can be activated, the most relevant scenario is that individual aerosol particles may act as condensation nuclei, accrete hydrocarbons and nitriles with more or less efficiency depending on solubility properties of the aerosols, and rain out when they pass through saturated regions of the troposphere (Loreng 1993a; McKay et al. 2001). However, observational evidence for a dense, persistent and ubiquitous cloud coverage in the supersaturated regions is not yet conclusive. Griffith et al. (1998; 2000) hemispheric integrated observations of Titan suggested a cloud cover. Titan's large cloud system that might have been observed in September 1995 Griffith et al. 1998) displayed cloud tops at an altitude of $z \sim 15 \pm 10 \mathrm{~km}$, covering about $10 \%$ of Titan's disk, and seemed to live for more than 2 days. Analysis of more recent spectra (Griffith et al. 2000) suggested another identification of tropospheric clouds. It revealed that clouds should reside at the altitude of $z \sim 27 \mathrm{~km}$. These clouds covered $\sim 0.5 \pm 1 \%$ of the moon's disk, and 
dissipated in only 2 hours. Thus, if clouds exist, they seem to be patchy, occupying only a fraction of Titan's disc. It may also be an intense but transient and fickle phenomena, making them even more difficult to observe and firmly identify.

Several models treating condensation in Titan's saturation region have been developed (Toon et al. 1988; Frère et al. 1990; Courtin et al. 1995; Samuelson and Mayo 1997), aiming at the determination of cloud properties. Toon et al. (1988) and Courtin et al. (1995) studied the characteristics of hypothetical pure methane clouds, considering atmospheric radiative properties. In particular, Toon et al. (1988) assumed that if the mixing ratio of methane exceedzd $2 \%$ by volume near and below the tropopause, it would reach (and even exceed) saturation level, triggering its probable condensation. Re-examining the Voyager IRIS infrared spectra of Titan, Toon et al. (1988) obtained an optimal fit when adding a methane cloud composed of droplets with a radius between $50 \mu \mathrm{m}$ and $3 \mathrm{~mm}$ and a density between 1 and $3500 \mathrm{~m}^{-3}$. This cloud cover, that can be considered as an ubiquitous homogeneous layer in addition to the aerosol haze, should extend from $10 \mathrm{~km}$ to $30 \mathrm{~km}$. The new re-interpretation of IRIS spectra led Courtin et al. (1995) to quite different conclusions. Their results, in best agreement with the data, did not contain a cloud layer. They found however that if a condensed $\mathrm{CH}_{4}$ cloud is added, it must have a mean particles radius of about $50-60 \mu \mathrm{m}$ and be located near the tropopause (about $40 \mathrm{~km}$ in altitude), though they could not put constraints on its vertical extent. A combination of cloud characteristics inferred from Toon et al. (1988) and Courtin et al. (1995) are summarized in Table 1.

\section{[Table 1]}

Frère et al. (1990) was the first to present a microphysical approach for conden- 
sation processes in Titan's low atmosphere, resulting in an estimation of the vertical radius and density distribution of aerosols. They elaborated a model dedicated to the determination of the distribution and chemical composition of the particles in the low atmosphere by taking into account differential condensation of several atmospheric compounds on aerosols in the cold trap region, in addition to classical transportation and collection processes. In their model condensation nuclei swell up, progressively covered with concentric layers of volatile compounds as soon as they reach saturation; supersaturation is not allowed. They constrained the size of particles by the volume of material available for condensation. They found that no significant condensation occurs above $100 \mathrm{~km}$. The gas to liquid or solid phase transition starts modifying the particle structure below $90 \mathrm{~km}$. From 0.1 to $1 \mu \mathrm{m}$ around $100 \mathrm{~km}$, the particle mean radius increases rapidly due to sustained accretion and reaches a few tens of microns at $85 \mathrm{~km}$. At this stage of the condensation process, the major constituents surrounding aerosols are nitriles, mainly $H C N$ and $C_{4} N_{2}$ in solid state. A growing drizzle takes place down to the tropopause. Below $70 \mathrm{~km}$, condensation of propane $\left(C_{3} H_{8}\right)$ becomes predominant, then come $C_{2}$ hydrocarbons (with decreasing altitude: $\mathrm{C}_{2} \mathrm{H}_{2}, \mathrm{C}_{2} \mathrm{H}_{6}$ and $\mathrm{C}_{2} \mathrm{H}_{4}$ ). Between $30 \mathrm{~km}$ and the surface, the particle radius becomes greater than $200 \mu \mathrm{m}$, reaching a maximum of $\sim 900 \mu \mathrm{m}$ at $11 \mathrm{~km}$. At these altitudes, liquid methane is the main constituent that condenses. Below $11 \mathrm{~km}$, the strong positive temperature gradient triggers methane layer evaporation of the droplets. The fusion/sublimation rate is moderate until $2 \mathrm{~km}$ above the surface. Then, the process becomes very efficient and removes almost all the liquid around the aerosols. The particle radius decreases to about $50-100 \mu \mathrm{m}$. That gives rise to a mist of ethaneenriched aerosols just above the surface (a "ghost" of the raincloud, consistent with 
considerations by Loreng (1993a)). Variations of the droplet density follow those of the radius but in the opposite way due to collection processes. More recent studies of rain occurence in Titan's lower atmosphere (Samuelson and Mayo 1997) led to similar conclusions as those of Frère et al. (1990). They obtained the same altitude for the maximum particle size $(z \sim 11-12 \mathrm{~km})$ and roughly the same size profiles versus altitude. The experimental work of McKay (1996) and recently Coll et al. (1999a) argued in favour of droplet chemical structure and size proposed by Frère et al. (1990) (Fig. 1-(b)). McKay (1996) and Coll et al. (1999a) demonstrated the insolubility of aerosol material in hydrocarbons and their relative solubility in nitriles. It is also consistent with the identification of nitriles in solid phase in Voyager IRIS spectra $\left(C_{4} N_{2}\right.$ Khanna et al. 1987; Coustenis et al. 1999) and $\mathrm{HCN}, \mathrm{HC}_{3} \mathrm{~N}, \mathrm{CH}_{3} \mathrm{CH}_{2} \mathrm{CN}$ (Coustenis et al. 1999 ) that could constitute a $10 \mu \mathrm{m}$-hail around the altitude of $90 \mathrm{~km}$ ). Aerosols might need a first nitrile layer to activate hydrocarbon condensation, as predicted by Frère et al. (1990) (Fig. 1-(b)).

\section{[Figure 1]}

\subsection{Surface}

Very little is known about the surface of Titan, which is hidden from view by the organic haze. Voyager 1 and 2 flybys allowed some progress in the knowledge of the puzzling nature of the satellite's surface, though they failed to directly reveal surface details. Surface properties were only indirectly inferred from the atmosphere characterization performed by the spacecrafts. Voyager 1 and 2 flybys allowed the determination of the atmospheric properties with an accuracy such that it was possible to propose some new and more relevant models for Titan's surface nature and to postulate the existence of a 
deep, global ocean of hydrocarbon (Lunine et al. 1983). The fact that methane is likely to be depleted in the stratosphere within barely 10 million years due to a photolytical sink, coupled with the fact that Titan's surface temperature is close to the triple point of methane, supports the idea that Titan should possess a liquid hydrocarbon reservoir at its surface or at least in its subsurface (Eshleman et al. 1983).

Observations have become available which suggest that Titan is not covered by an ubiquitous ocean. Subsequent ground-based radar observations, passive microwave radiometry and near-infrared observations give us today a new insight in the current understanding of Titan's surface. Direct radar sensing of Titan's surface at a wavelength of $3.5 \mathrm{~cm}$ (Muhleman et al. 1990) revealed a surprisingly high reflectivity (much higher than the reflectivity of a global methane-ethane ocean) but still lower than that of the icy Galilean satellites. Radar reflectivity was also extremely variable from one night to the other, suggesting a heterogeneous surface. Passive radiometry undertaken at the same time by Muhleman et al. (1990) suggested an emissivity of about 0.9 at similar wavelengths (higher than those of Europa and Ganymede, but similar to that of Callisto). The only way they found to reconcile high emissivity and high reflectivity was to consider a surface covered with "dirty" ice (ice contaminated by organic compounds). This hypothesis was recently confirmed with the help of near-infrared observations from HST (Hubble Space Telescope), CFH (Canada-France-Hawaii) and, AEOS (Advanced Electro Optical System) telescopes in the methane-window regions $(0.94,1.08,1.28,1.58,2$ and $5 \mu m)$, where it may be possible to probe the surface between methane absorption bands. These observations are consistent with dirty ice, including areas of hydrocarbon seas (Lorenz 1993b; Lorenz and Lunine 1997). Coustenis et al. (2001) have investigated the nature of ice present at the surface of Titan. 
They took images (albedo maps) of Titan's surface at 1.3 and $1.6 \mu m$ with a resolution high enough to resolve Titan's disk with 20 pixels. They observed the same bright feature at the equator that was previously observed by the HST (Smith et al. 1996) and the Keck I telescope (Gibbard et al. 1999). That allowed them to propose some candidates spectrally relevant for the icy composition of the different (bright/dark) regions observed. By comparison to other surface spectra (Coustenis et al. 1995; 1997), they suggested the presence of methane (or ethane) frost, ammonia ice, and water ice on Titan's surface, probably covered by sediments of organics, as foreseen by photochemical atmospheric models. Toon et al. (1980) predicted indeed that the aerosols produced in the upper stratosphere should settle and deposit on the ground at the rate of $0.1 \mu \mathrm{m}$ each year, to form a layer of about $400 \mathrm{~m}$ over geological times. The hydrocarbon and nitrile liquids they drag towards the surface are expected to stream down the relief and fill lakes or seas, whereas solid organic cores of the droplets should form sedimentary layers. It is nevertheless impossible to discriminate whether aerosols are intimately mixed with ice or whether they constitute a dark organic layer over an icy surface with some bright regions of exposed ice. The aerosols falling over a lake or a sea do not sink and create an organic layer, due to their poor solubility into hydrocarbon liquids.

\section{Electromagnetic characterization of titanian ma- terials}

\subsection{Electromagnetic characterization of tholins}

Electric properties of titanian aerosol analogs were often measured in visible-UV range, but are poorly known in the microwave range. The only published value for dielectric 
constant at GHz frequencies is the one taken from Khare et al. (1984) measurements. They found a permittivity of $4.71-j 0.013$ at $f \sim 300 \mathrm{GHz}$. Considering that tholins are major compounds of Titan's atmosphere susceptible to interact with Cassini radar electromagnetic wave, we performed a set of measurements of aerosols' analogs permittivity in the $\mathrm{GHz}$ frequency range.

\subsubsection{Synthesis of tholins}

Since the early work of Khare and Sagan (1973), many laboratory simulations of Titan's atmosphere have been achieved. Such experiments were conducted by irradiation with UV light, electrical discharge, or energetic electrons, of a gas mixture close to the Titan's atmosphere composition, isolated from contamination in a glass recipient - the reactor. Without any exceptions, these simulations produced a solid organic material - termed tholin - which has optical properties similar to those needed to match the geometric albedo of Titan (Rages and Pollack 1980; McKay et al. 1989).

In order to get tholin samples for further dielectric measurements, we conducted experiments in the LISA laboratory where a reactor essentially dedicated to the study of the titanian atmospheric chemistry was designed. A detailed description of the experimental devices can be found in Coll et al. (1999a) and Coll et al. (1999b). According to McKay et al. (2001), this experiment promises to give the most accurate simulation of Titan's haze formation, as the dinitrile $C_{4} N_{2}$ (detected in solid phase on Titan), has been identified for the first time as a product of the simulation, this clearly constitutes a validation of the experiment (Coll et al. 1999b).

In our case, we performed three titanian atmosphere simulations with a low pressure flux ( 1-4 mbar of total pressure) of a $N_{2} / \mathrm{CH}_{4}$ mixture (in a 98:2 proportion). 
A glass tablet or a silica cylinder was inserted into the reactor where tholins are deposited to form a film. In order to collect tholin samples, the reactor was installed inside a glove box filled with nitrogen to avoid contamination of the sample by the atmosphere in the room, in particular oxygen atoms, before electromagnetic characterization. Finally, the volume of deposited tholins - an essential parameter for future permittivity measurements - is determined using scanning electron microscopy to measure the thickness of the sample. Table 2 summarizes synthesis conditions and volume estimations for each set of experiments.

\section{[Table 2]}

\subsubsection{Dielectric constant measurements}

Tholin samples produced in the LISA reactor were characterized at the PIOM laboratory in order to measure their dielectric properties in the GHz range. Permittivity measurements were performed using a rectangular resonant cavity pierced on its top with a hole used to insert the sample. For the purpose of these experiments, we used two different kind of cavities : one at $10 \mathrm{GHz}$ (i.e. $\lambda=3 \mathrm{~cm}$ ) and a second one at 2.45 GHz (i.e. $\lambda=12.2 \mathrm{~cm}$ ). As the change in the dielectric constant value should be small in the range $1-10 \mathrm{GHz}$, the choice of a cavity was made only because of the sample holder shape : the $10 \mathrm{GHz}$ cavity is too small to allow a large rectangular hole on its top center and only a cylindrical sample holder can be used. Each cavity is composed of a wave-guide short-circuited at each end. Excitation and detection of resonance inside the cavity are done by co-axial transitions mounted on connectors linked to a network analyzer (ANRITSU 37325A).

The resonance modes that can be established in a cavity are deduced from the 
theory of wave propagation along a wave-guide. These modes are characterized by three integer indices $m, n$ and $p$. In the case of a rectangular cavity, TE01 $p$ resonance modes are usually used ( $m=0$ and $n=1$ as dominant mode, $p$ representing the number of maxima of the electric field along the wave-guide length). In particular, the index $p$ is chosen odd $(p=3)$ in order to ensure the position of a maximum in the center of the cavity, where we insert the sample. The sample holder symmetry axes are set in a way that they are parallel to the electric field established in the cavity, in order to minimize perturbations due to depolarization effects.

Once the cavity is connected to the network analyzer, we first introduce an empty sample holder into the cavity to measure the resonance frequency $F_{0}$, and the quality coefficient $Q_{0}$ of the cavity as blank references. Then, we insert an identical sample holder - same glass/silica volume - but covered with a tholin film. The introduction of a tholin sample triggers a deviation from the resonance frequency, $\Delta F$, and an additional attenuation conducting to a new quality factor $Q_{1}$. As it is well established for resonant cavity experiments, the measurement of $\Delta F, Q_{0}$, and $Q_{1}$ allows to directly obtain the dielectric constant $\varepsilon^{\prime}-j \varepsilon^{\prime \prime}$ of the sample thanks to the relations (Boudouris 1971):

$$
\begin{gathered}
\frac{\Delta F}{F_{0}}=-\alpha\left(\varepsilon^{\prime}-1\right) \\
\Delta\left(\frac{1}{Q_{1}}-\frac{1}{Q_{0}}\right)=2 \alpha \varepsilon^{\prime \prime}
\end{gathered}
$$

with $\alpha=\alpha_{0} \times V_{\text {sample }}, V_{\text {sample }}$ being the volume of the tholin sample and $\alpha_{0}$ being the cavity filling coefficient (ratio between the tholin sample + sample holder volume 
and the cavity volume).

For each set of tholin samples (see Table 2), we obtained a value for the tholin dielectric constant. Results of our measurements are shown in Table 3. While real part of the dielectric constant shows a very little variation $(\sim 10 \%)$, the imaginary part varies by a factor of 50 . This variation is due to the poor estimation of factor $Q$, which is highly sensitive to the volume of material introduced in the cavity. An accurate value for this volume is very hard to obtain.

\section{[Table 3]}

\subsection{Electromagnetic characterization of other titanian mate- rials in liquid and solid states}

Apart from tholin characterization, we also searched in the literature for values of permittivities of materials of interest for radar sounding of Titan's atmosphere and surface, in the microwave range.

\subsubsection{Pure liquid methane}

The dielectric properties of pure liquid methane and their implications for Titan's study were investigated by Thompson and Squyres (1990). They published a rough estimate of $\varepsilon_{r}$ for liquid $\mathrm{CH}_{4}$ around $94 \mathrm{~K}: \varepsilon^{\prime} \sim 1.7$ and $\varepsilon^{\prime \prime} \sim 1.5 \times 10^{-2}$. This is fully consistent with the value found in Handbook of Chemistry and Physics (1988-1989) around $100 \mathrm{~K}$ in the hundreds of $\mathrm{MHz}$ range. 


\subsubsection{Titan's raindrops and hypothetical surface oceans: liquid hydrocar- bon and nitrile mixtures}

According to Frère et al. (1990), Titan's raindrops are primarily made of light hydrocarbon liquids instead of pure methane, progressively accreted in concentric layers around aerosols. During the fall of the raindrops, internal dynamics stirs the liquid $\mathrm{CH}_{4}$ and $\mathrm{C}_{2} \mathrm{H}_{6}$ into a homogeneous mixture. Such a mixture was the subject of a few experimental studies aiming at determining its dielectric properties. Muhleman et al. (1990) indicate that the real part of the dielectric constant for liquid hydrocarbons is well known to be in the range of 1.6 to 2 and that loss tangents are of the order of $10^{-3}-10^{-4}$ in the GHz range. Singh and Miller (1979) found a real part of permittivity between 1.77 and 1.9 for methane-ethane mixtures at low temperature (typically around $100 \mathrm{~K}$ ) and Ulamec et al. (1992) obtained values between 1.71 and 1.95 around $94 \mathrm{~K}$. The values from Singh and Miller (1979) were obtained using a fit to an equation derived from the Clausius-Mossotti function, on the basis of liquid compressibility considerations, and those coming from Ulamec et al. (1992) were inferred from capacity measurements. We have no indications about what could be frequency range they considered. However, such values are consistent with dielectric constant measurements of Sen et al. (1992) for liquid alkanes and hydrocarbon mixtures at $1.2 \mathrm{GHz}$ and 298 K.

\subsubsection{Titan's surface: hydrocarbons and water ice}

Titan's surface is supposed to be composed of various icy materials $\left(\mathrm{H}_{2} \mathrm{O}\right.$ ice, hydrocarbons in solid state) due to its low $94 \mathrm{~K}$ temperature (Lellouch et al. 1990), probably fractionally covered or mixed with tholin material. It then should present a high and 
contrasted reflectivity in the radar wavelength range. Dielectric constants of such materials were experimentally measured. We had access to precise values for the real part of their permittivity, but only to rough estimations for the imaginary part: $\mathrm{H}_{2} \mathrm{O}$ ice corresponds to $\varepsilon^{\prime} \sim 3.1$, measured around $10 \mathrm{GHz}$ and valid within the temperature range from -1 to $-185^{\circ} \mathrm{C}$ (Ulaby et al. (1982), vol. 3, appendix E, p. 2028), and a $\mathrm{CH}_{4}-\mathrm{C}_{2} \mathrm{H}_{6}$ ice mixture has $\varepsilon^{\prime} \sim 2-2.4$ in the same wavelength range (Thompson and Squyres 1990).

All the dielectric constants of interest for radar sounding of Titan are summarized in Table 4.

\section{[Table 4]}

\section{Simulation of the CASSINI radar behaviour}

\subsection{Testing the radar penetration through the atmosphere}

In this part, we present simulations of the CASSINI Radar experiment in active modes. This section mainly deals with the dielectric models we have developed to quantify the impact of condensates in Titan's atmosphere.

We used in our calculations the complex dielectric constant we measured for tholin material. Uncertainties on the permittivity of tholins have repercussions on the attenuation we calculate: concerning atmospheric transmission simulations, the attenuation does not vary linearly with the dielectric constant. The minimum value for attenuation was obtained with $\varepsilon^{\prime}=2.1$ and $\varepsilon^{\prime \prime}=0$, and the maximum attenuation corresponds to $\varepsilon^{\prime}=2.1$ and $\varepsilon^{\prime \prime}=0.1$. For the preliminary results on homogeneous atmosphere models, we considered the mean value measured for the dielectric constant 
of tholins: $\varepsilon_{r}=2.2-j 0.05$.

\subsubsection{Description of the Rayleigh-Mie scattering model}

We consider the propagation of a radar wave through Titan's atmosphere. The simple model we developed enables us to determine the attenuation an incident radar wave (emitted power $P^{i n c}$ ) will undergo while crossing the dense atmosphere of Titan. The attenuation in decibels is given by

$$
A t t_{\text {total }}(d B)=A t t_{\text {gases }}+A t t_{\text {particles }}=10 \log _{10}\left(\frac{P^{\text {ground }}}{P^{\text {inc }}}\right)
$$

with $P^{\text {ground }}$ being the radar wave power reaching the surface of Titan.

The gaseous component is considered with no ambiguity as totally transparent for the radar and its permittivity is set equal to one. Thus,

$$
\operatorname{Att}_{\text {gases }}(d B)=0
$$

Only the condensate - aerosols, hail and rain particles - component could have sufficient size, density and permittivity to interfere with the radar wave. In this case, we can reasonably simulate the medium that the wave will encounter before reaching the surface by a diluted medium composed of dielectric spheres in suspension in vacuum. Only single scattering and absorption of the incident wave are considered here and we can then write for an homogeneous atmosphere:

$$
\frac{P^{\text {ground }}}{P^{\text {inc }}}=e^{\left.-\left[C\left(\sigma_{\text {scat }}+\sigma_{a b s}\right) \frac{h}{\cos \theta}\right)\right]}
$$


with,

$C$, particle density,

$h$, thickness of the atmosphere,

$\theta$, incidence angle of radar wave (set to $0^{\circ}$ for the altimetric mode),

$\sigma_{\text {scat }}$, single scattering cross section,

$\sigma_{a b s}$, absorption cross section.

Cross sections for spherical scatterers are taken from Rayleigh and Mie theories. Transition between the Rayleigh and Mie regimes occurs when the particle radius is greater than $r_{l i m}=0.05$. Rayleigh formalism is valid only for small particles in comparison to the wavelength. In the case of the Cassini Radar, the upper limit to the radius $r_{l i m}$ of the scatterer is set to $1.08 \mathrm{~mm}$.

Rayleigh scattering and absorption cross sections can be analytically solved and are given by โshimaru (1997):

$$
\begin{gathered}
\sigma_{\text {scat }}=\frac{128 \pi^{5} r^{6}}{3 \lambda^{4}}\left|\frac{\varepsilon_{r}-1}{\varepsilon_{r}+2}\right|^{2} \\
\sigma_{a b s}=\frac{8 \pi^{2} r^{3} \varepsilon^{\prime \prime}}{3 \lambda}\left|\frac{3}{\varepsilon_{r}+2}\right|^{2}
\end{gathered}
$$

Mie scattering cross sections are numerically computed by means of a classic BHMIE code taken from Bohren and Huffman (1983). The complex parameter $\varepsilon_{r}=\varepsilon^{\prime}-$ $j \varepsilon^{\prime \prime}$ represents the dielectric constant of the spheres of radius $r$. It should be frequencydependent and was experimentally measured around the Cassini Radar experiment frequency (cf. section 3).

\section{[Figure 2]}

In our model (for heterogeneous atmosphere cases), the atmosphere of Titan is 
vertically cut off into homogeneous layers containing particles of fixed size and density (Fig. 2). We then compute the ratio between outgoing and incident flux $P_{i}^{\text {out }} / P_{i}^{\text {inc }}$ for each layer $i$ of thickness $h_{i}$. The resulting final attenuation is the sum of attenuations induced by each layer $i$. It is given by :

$$
\operatorname{Att}_{\text {total }}(d B)=\sum_{i} A t t_{i}=\sum_{i} 10 \log _{10}\left(\frac{P_{i}^{\text {out }}}{P_{i}^{\text {inc }}}\right)
$$

Equation (5) indicates that the part of the flux scattered or absorbed by the particles is lost. It reproduces well what could happen to a wave in single scattering regime along the radar line-of-sight.

\subsubsection{Homogeneous atmospheres}

We computed the attenuation of the centimetric signal emitted by the Cassini Radar instrument induced by the presence of particles in a ideal Titan-like homogeneous atmosphere. In this simple case, we considered single crossing of the wave through a totally homogeneous atmosphere, made of a unique layer with a single mode of particle size, density and dielectric properties.

The thickness $H$ of the homogeneous layer was constrained by the aerosol haze extension within Titan's atmosphere and was fixed to $h=500 \mathrm{~km}$. We fixed $\varepsilon_{r}$ to its experimental mean value of $2.2-j 0.05$. The only free parameters in our simulation were particle radius and density. We decided to put a constraint on these parameters from extreme values found in literature: density ranges between unity and a maximum around $10000 \mathrm{~cm}^{-3}$, and radius ranges between a few nanometers and a high value of $20 \mu \mathrm{m}$. Attenuations induced by such particles over a $500 \mathrm{~km}$ thick layer are shown 
in Fig. 3-(a). Each point of the figure represents the attenuation calculated for a unique atmospheric scenario, i.e a unique pair of particle radius and density over a homogeneous Titan atmosphere.

\section{[Figure 3]}

The detection threshold (noise equivalent $\sigma_{0}$ ) of the Cassini Radar instrument is limited to about $-25 d B$ (Elachi et al. 1991). It means that, with the hypothesis that all the power reaching the surface of Titan is backscattered to the radar, a signal attenuation greater than $12.5 \mathrm{~dB}$ for the first crossing of the atmosphere would lead to no signal detection by the instrument. Figure 3-(b) is a $2-\mathrm{D}$ representation of the variation of the attenuation versus particle radius and density. It shows the position of the $12.5 \mathrm{~dB}$ attenuation limit, and attenuation greater than $12.5 \mathrm{~dB}$ for only one atmosphere crossing is represented in gray on the Fig. 3-(b)). Some radius/density combinations are then prejudicial to the Radar experiment and its main objective of surface imaging. The model we considered here is very simple but shows that it is worthwhile to study the possible impact of atmospheric particles (aerosols, hail particles, drizzle and rain droplets) on the radar experiment. It allows also to define some first order ranges of radius and density for which the radar could encounter

difficulties to see the surface of Titan. It would be the case with, for example, a $500 \mathrm{~km}$ thick atmosphere constituted of particles of $6 \mu \mathrm{m}$ radius with a $1000 \mathrm{~cm}^{-3}$ density, which is not completely unexpected or unrealistic at first order when we refer to distributions retrieved from observations or microphysical calculations including rain occurrence (particles are then concentrated in a thinner layer, but are much bigger than ten microns (Toon et al. 1988; Frère et al. 1990)). The scattering cross section increases 
with the sixth power of the radius of the scatterers and constitutes the more sensitive parameter. These first results lead us to the conclusion that Titan's atmosphere might not be as transparent to Cassini radar frequencies as it was expected. Radar pulses could at least be affected and distorted, even if they encounter smaller particles than those we considered in this section.

\subsubsection{Heterogeneous atmospheres and cloud layers}

In this section, we take into account as a modeling refinement the possible heterogeneity of aerosol properties with altitude. We do not treat the atmosphere as an ideal homogeneous layer anymore but as a more complex medium as predicted by numerous published models.

We used the heterogeneous distribution of particles discussed in section 2 in order to simulate a more realistic Titan's atmosphere (see Fig.가.(a)). We also included as a reference two semi-homogeneous models for Titan's atmosphere inferred from Pioneer and Voyager image analysis (Smith et at. 1981; 1982; Tomasko and Smith 1982). Highresolution views of the limb at high-phase angles revealed the presence of several layers of aerosols: an optically thin layer of haze $\sim 50 \mathrm{~km}$ thick roughly $100 \mathrm{~km}$ above a main aerosol layer. The aerosol particle average size in the main haze layer was found to be between 0.1 and $0.5 \mu \mathrm{m}$ for a real part of refractive index $n_{r}$ chosen between 1.7 and 2 at visible wavelengths. For the upper haze layer, a mean value for the particle radius was taken to $0.3 \mu \mathrm{m}$. Particle densities were calculated by Toon et al. (1980). They found $10^{4} \mathrm{~cm}^{-3}$ for the first tenth of the visible optical depth in Titan's atmosphere and $10^{3} \mathrm{~cm}^{-3}$ at an optical depth of 1 . In addition to the detached haze layer, and above it, Rages and Pollack (1983) discovered a small but persistent feature in the 
Voyager 2 extinction profiles, characteristic of another haze layer with the following physical properties: roughly $50 \mathrm{~km}$ thick, composed of $3 \mu \mathrm{m}$-particles with a density of $\sim 0.2 \mathrm{~cm}^{-3}$ (cf. Table 5). We considered a mean aerosol permittivity $\varepsilon_{r}=2.2-j 0.05$. Errorbars on attenuation come from uncertainties on tholin permittivity (the minimum value for attenuation was calculated with $\varepsilon^{\prime}=2.1$ and $\varepsilon^{\prime \prime}=0$, and the value maximum with $\varepsilon^{\prime}=2.1$ and $\varepsilon^{\prime \prime}=0.1$.

We considered also the probable occurrence of hydrocarbon rain at low altitudes. It was treated differently according to two scenarios: (1) We simulate the rain as another independent layer in addition to aerosols Toon et al. (1988) and Courtin et al. (1995) approach) and, (2) we consider rain as the result of continuous growing of aerosols (Frère et al. (1990) approach). In case (1), we construct the cloud cover by substituting the "dry" particle distribution (two homogeneous multi-layer models as defined earlier and models presented on Fig. 나(a)) by a homogeneous layer containing methane droplets inspired by Toon et al. (1988) (cf. Table 1). The vertical extension of the cloud is supposed to range between altitudes of 30 and $10 \mathrm{~km}$. We fixed an average methane droplet radius to $2 \mathrm{~mm}$ and their permittivity to $\varepsilon_{r}=1.7-j 0.015$, based on the hypothesis that the raindrops are only composed of pure liquid methane and that the tholin nuclei can be neglected (the liquid phase hugely dominates the composition of the droplet). The way we control the density of the cloud was inspired by recent work of Samuelson and Mayo (1997) and Guez et al. (1997). They suggested that liquid hydrocarbons may condense only from a limited subset of the aerosols falling through the saturated layer, in particular for kinetic reasons. Guez et al. (1997) introduced the concept of nucleation rate. Indeed, the condensation process efficiency is highly dependent on the contact angle of condensed materials on the nucleus. This is an 
essential parameter to estimate the compatibility between nucleus and the condensed phase. As contact angles are very unconstrained parameters, we treated the problem in a simple way thanks to a condensation efficiency factor $f$ that can be free to vary between 0 and $100 \%$. Using this coefficient, we simulate the fact that only a fraction of aerosols can supply the cloud in droplets at the condensation level: for an atmosphere sampled every kilometer, cloud concentration is then given by $C_{\text {droplets }}(z=30 \mathrm{~km})=$ $f \times C_{\text {aerosols }}(z=31 \mathrm{~km})$. We checked that densities obtained for the top of the methane cloud $(z=30 \mathrm{~km})$ never exceed the limits imposed by Toon et al. (1988), whatever higher aerosol distribution can be. The f parameter was fixed equal to $10^{-4 \%}$, giving particle concentrations at the cloud top of $1000,1000,8$, and $250 \mathrm{~m}^{-3}$ respectively for the atmospheric models A, B, C and D (cf. Table 5). The cloud's particle radius and concentration are then constant with respect to the altitude from the cloud top $(30 \mathrm{~km})$ to its base $(10 \mathrm{~km})$. Aerosols which don't participate in the condensation process are neglected, and Titan's atmosphere is then only constituted of a homogeneous cloud of methane rain droplets between 30 and $10 \mathrm{~km}$. Below $10 \mathrm{~km}$, as Lorend (1993a) showed, pure methane droplets should evaporate and resupply aerosol layers, forming a "ghost" mist of aerosols close to the surface. In order to simulate rain sublimation in the last kilometers of Titan's troposphere, we stop the rain layer below $10 \mathrm{~km}$ and replace it by the "dry" scenario we used to describe the atmosphere above $30 \mathrm{~km}$.

In case (2), we simply used the heterogeneous distribution computed by Frère et al. (1990) (Fig. 마(a)) as the complete description of the fate of particles over the full extent of Titan's atmosphere, even at low altitudes where condensation should occur. As they treated the differential condensation of a great number of hydrocarbons and nitriles, we chose an averaged permittivity for the raindrops inferred from those 
measured for a homogeneously mixed hydrocarbon-nitrile liquid: $\varepsilon_{r}=1.8-j 0.002$ (as for case (1), electrical properties of the condensation nuclei were neglected). In this case, the artificial factor $f$ has no sense anymore. All aerosols participate in the condensation process. The density and the size of the rain droplets below $100 \mathrm{~km}$ are thus self-determined by the calculations of Frère et al. (1990) thanks to modeling of collisional and sticking processes.

All the models used in our calculations are summarized in Table 5.

\section{[Table 5]}

\section{[Figure 4]}

Figure 4 shows the results obtained for the nine models described in Table 5. Cases A, B, C and D correspond to attenuations induced by a dry atmosphere, only constituted of aerosol hazes. The attenuation never exceeds $-0.02 \mathrm{~dB}$, even for the least favorable scenario B (containing the highest particle size and density over the greatest part of the atmosphere), and are globally negligible $\left(\leq-10^{-3} \mathrm{~dB}\right)$. We can conclude that, without rain occurrence in the troposphere, Titan's atmosphere should be totally transparent for the $13.78 \mathrm{GHz}$ radar of the Cassini orbiter. When we consider cases $\mathrm{A} \sharp, \mathrm{B} \sharp, \mathrm{C} \sharp, \mathrm{D} \sharp$ and $\mathrm{E}$, the conclusions are quite different. The addition of a rain layer in the middle troposphere increases the signal attenuation by at least four orders of magnitude. For $\mathrm{D} \sharp, \mathrm{A} \sharp$ - $\mathrm{B} \sharp$ (rain attenuation overflows the attenuation induced by aerosols and the difference between scenario $A \sharp$ and $B \sharp$ is then small; thus $A \sharp$ and $B \sharp$ can be considered as one unique scenario), and E models, attenuation reaches respectively $-5 \mathrm{~dB},-20 \mathrm{~dB}$ and $-25 \mathrm{~dB}$. On the other hand, the value of attenuation is still low for scenario $\mathrm{C} \sharp(-0.17 \mathrm{~dB})$, due to the fact that the rain cloud modeled for this case presents 
a very low density. This parameter is controlled by the factor $f$, fixed to $10^{-4 \%}$, and the density of aerosols just above $30 \mathrm{~km}$. For scenario $\mathrm{C} \sharp$, the cloud has a density of only $8 \mathrm{~m}^{-3}$, in comparison to models $\mathrm{A} \sharp$ and $\mathrm{D} \sharp$ which have a raincloud density of respectively $1000 \mathrm{~m}^{-3}$ and $250 \mathrm{~m}^{-3}$. We have to keep in mind that the titanian aerosol modeling of McKay et al. (1989) (scenario $\mathrm{C}$ and $\mathrm{C} \sharp$ ) was rather simple, and the aerosol density it predicts around $30 \mathrm{~km}$ is certainly less accurate than the one obtained from Erère et al. (1990) (scenario E) and Cabane et al. (1992) (scenario D and $\mathrm{D} \sharp)$. We are convinced that, even if clouds in Titan's atmosphere are transient and rare phenomena, they could surely affect the radar signal. For two of the scenario we studied ( $\mathrm{A} \sharp$ and $\mathrm{E}$ ), clouds should totally attenuate the radar pulse before it reaches Titan's surface. For model $\mathrm{D} \sharp$, it should also cause sufficient attenuation to possibly blur surface images by diminishing the contrast between distinct surface echoes.

\section{[Figure 5]}

The rain layer we used in addition to models $\mathrm{A}, \mathrm{B}, \mathrm{C}$, and $\mathrm{D}$ in order to simulate the condensation process in Titan's low atmosphere is intrinsically artificial in its construction. We explored the way the attenuation may vary if we free some badly constrained parameters of this layer: radius of droplets and condensation efficiency $f$. The radius can vary between $0 \mathrm{~mm}$ (no rain) and $4.5 \mathrm{~mm}$ (limit imposed by aerodynamics (Lorenz 1993a)). For the parameter $f$, even if there are no means at the present time to physically impose a constraint on it, we can consider that the value we chose ( $f=10^{-4 \%}$, i.e. one aerosol per million acts as a condensation nucleus) in order to match the cloud densities predicted by Toon et al. (1988) is very low. Higher values (up to $0.1 \%$ ) cannot be totally excluded and should cause much more attenuation. We 
present in Fig. 5 the results of this parametric study: the attenuation as a function of rain droplet radius (Fig. 5-(a)) and condensation efficiency (Fig. 5-(b)) for models A $\sharp-$ $\mathrm{B} \sharp, \mathrm{C} \sharp$ and $\mathrm{D} \sharp$. The increase of $r$ and $f$ induces a drastic rise of attenuation for all the cases considered. Attenuations are much greater than unity as soon as $r$ reaches $2 \mathrm{~mm}$, and $f$ reaches $0.001 \%$. Figure 5 demonstrates the high sensitivity of the attenuation to $r$ and $f$, which are unfortunately weakly constrained.

\subsection{Surface reflectivity}

As aerosols are supposed to deposit on Titan's surface and form a "dirty ice" mixture, we tried to simulate the radar response of a surface covered with tholins. It allows us to refine the first hypothesis we made in the previous section of a perfectly reflecting surface (i.e. all the energy reaching Titan's surface is backscattered to the instrument).

Since the Cassini Radar experiment will operate in the Ku-band ( $f=13.8 \mathrm{GHz}$, $\lambda=2.17 \mathrm{~cm}, \mathrm{HH}$ polarization (Elachi et al. 1991), most of Titan's surface is likely to appear as rather rough for the radar (Dierking 1999). We shall then consider surface scattering models developed for medium rough to very rough surfaces, i.e. the Physical Optics (PO) model and the Geometric Optics (GO) model, which were derived from the Kirchhoff model under the scalar approximation and the stationaryphase approximation respectively. These models are relevant to evaluate performances of a side-looking imaging radar. We shall consider here a single homogeneous layer covered by tholins (characterized by its averaged dielectric constant $\varepsilon=2.2-0.05 j$ ), water ice or liquid methane, and characterized by its surface roughness. The latter is defined by the surface correlation function $\rho(x)$ (a Gaussian function is assumed here), the height standard deviation $\sigma$, and the correlation length $L$ (cf. Fig. 6). 


\section{[Figure 6]}

The PO model validity range is defined by the following conditions:

$$
\frac{\sqrt{2} \sigma}{L}<0.25, \quad k L>6 \quad \text { and } \quad L^{2}>2.76 \sigma \lambda
$$

where $k$ is the wave number of the incident plane wave $(k=2 \pi / \lambda)$. The HH noncoherent scattering coefficient is then given as a function of the incidence angle $\theta$ by Ulaby et al. (1982):

$$
\sigma_{H H}^{0}(\theta)=2 k^{2} \cos ^{2} \theta \Gamma_{H}(\theta) e^{-(2 k \sigma \cos \theta)^{2}} \cdot \sum_{n=1}^{\infty}\left(4 k^{2} \sigma^{2} \cos ^{2} \theta\right)^{n} / n ! \int_{0}^{\infty} \rho^{n}(x) J_{0}(2 k x \sin \theta) x d x
$$

where $J_{0}$ is the zeroth-order Bessel function of the first kind, $\Gamma_{H}(\theta)=\left|R_{H}(\theta)\right|^{2}$ is the Fresnel reflectivity, and $\rho(x)=\exp \left(-x^{2} / L^{2}\right)$ is the Gaussian surface correlation function.

The GO model validity range is expressed by:

$$
(2 k \sigma \cos \theta)^{2}>10, \quad k L>6 \quad \text { and } L^{2}>2.76 \sigma \lambda
$$

and the $\mathrm{HH}$ (or VV) noncoherent scattering coefficient is given as a function of the angle of incidence $\theta$ by Fung and Eom (1981):

$$
\sigma_{H H}^{0}(\theta)=\frac{\Gamma(0) e^{-\tan ^{2}(\theta) / 2 m^{2}}}{2 m^{2} \cos ^{4} \theta}
$$

where $m=\frac{\sqrt{2} \sigma}{L}$ is the rms slope for a Gaussian surface and $\Gamma(0)$ is the Fresnel reflectivity evaluated at normal incidence: 


$$
\Gamma(0)=\left|\frac{1-\sqrt{\varepsilon / \mu}}{1+\sqrt{\varepsilon / \mu}}\right|^{2}
$$

(we consider here a magnetic permeability $\mu=1$ ).

\section{[Figure 7]}

Figure 7 presents the radar backscattered power for two types of surfaces: a relatively smooth surface with $\sigma=0.5 \mathrm{~cm}$ and $L=25 \mathrm{~cm}$ described by the PO model, and a rough surface with $\sigma=7 \mathrm{~cm}$ and $L=10 \mathrm{~cm}$ described by the GO model. Calculations were performed for surfaces covered by tholins, water ices and liquid methane. Uncertainties on experimental tholin dielectric constant were considered, but the resulting imprecision on backscattered power actually stays between the values obtained for water ice and liquid methane. For the mean look angle foreseen for the imaging mode of the Cassini radar $\left(\theta_{L} \sim 11^{\circ}\right.$ (Elachi et al. 1991)), we can see that the backscattered power for a smooth flat surface is very low (about -80 dB), much lower than the noise equivalent $\sigma_{0}$ of the instrument announced to be around $-25 \mathrm{~dB}$ (Elachi et al. 1991). On the contrary, a rough and flat surface should present a much higher return, about $-17 \mathrm{~dB}$. As a first approximation, the Cassini imaging radar should only see very rough regions covered by tholins (land surfaces?) whereas smooth and flat surfaces (seas and lakes ?) should appear as dark zones. Nevertheless, for non-flat smooth regions, Fig. 7 shows that slopes facing the radar with an incidence angle $\theta$ less than $7^{\circ}$ would produce a backscattered power higher than $-25 \mathrm{~dB}$. Considering the mean look angle $\theta_{L}$, it corresponds to a slope ranging between $4^{\circ}$ and $28^{\circ}$, which represent a large fraction of slope values that can be observed on planetary surfaces. Results obtained here should be of course considered as indicative, since very little is 
known about Titan's surface composition and roughness. In particular, due to the low loss tangent of tholins $\left(\tan \delta=\varepsilon^{\prime \prime} / \varepsilon^{\prime}=0.02\right)$ and other surface materials such as water ice, the penetration depth $D_{P}$ of the incident $\mathrm{Ku}$-band wave given by:

$$
D_{P}=\frac{\lambda}{4 \pi}\left\{\frac{\mu \varepsilon^{\prime}}{2}\left[\sqrt{1+\left(\frac{\varepsilon^{\prime \prime}}{\varepsilon^{\prime}}\right)^{2}}-1\right]\right\}^{-1 / 2}
$$

is about $10 \mathrm{~cm}$. This could give rise to some attenuation and volume scattering effects that could change the radar backscattered power computed from Eq. (I0) and (12). A mixture between silicate and tholins should also lead to higher values of $\varepsilon$, and then to a higher reflectivity of the surface.

If we make the link between the results we obtained for atmospheric attenuation and the surface backscattered power, it leads to more realistic conclusions for the attenuating role of the atmosphere. The surface should not be perfectly reflective for the radar wave as we hypothesized in the previous section. In the favorable case of a rough surface, the reflected signal could still lose $17 \mathrm{~dB}$, and the limit of the acceptable atmospheric attenuation should then be reduced to $-4 \mathrm{~dB}$ instead of -12.5 $\mathrm{dB}$ if considering a radar sensitivity limit of $-25 d B$. This dramatically increases the impact of an attenuating atmosphere on the Radar experiment (see Fig. 4 and 5 with the attenuation limit fixed at $-4 \mathrm{~dB})$.

\section{Conclusion and perspectives}

The Cassini mission has been designed to send a spacecraft to the planet Saturn, and deploy an instrument probe, Huygens, that will descend to the surface of Saturn's moon Titan. The radar instrument onboard the orbiter is expected to bring the scientific 
community new information to characterize the surface of Titan. We are convinced that correct interpretation of the measurements made with the Cassini Radar instrument requires simulations and laboratory measurements to anticipate possible atmospheric effects and then better invert and interpret radar data.

In this paper we presented a study of the behaviour of a $13.78 \mathrm{GHz}$ plane wave going through Titan's atmosphere and backscattered by its surface. Titan's atmosphere was modeled by a diluted medium filled with spherical particles of size, density and permittivity estimated from what could be found in the literature and laboratory experiments. We considered one homogeneous atmosphere model and five heterogeneous models including or not condensation that could occur in the lowest part of titanian atmosphere. In order to fix some parameters of our models, we conducted a series of experiments in order to derive the dielectric properties around $13.78 \mathrm{GHz}$ of Titan's aerosol analogs produced in laboratory.

The results we obtained in terms of radar power attenuation after crossing the simulated Titan's atmosphere are of two kinds:

- the "dry" heterogeneous atmospheric models, only taking into account the aerosol component, do not cause any attenuation and the radar wave will reach the surface of Titan without any losses. The particle radius never exceeds $1 \mu \mathrm{m}$ (far from the critical limit around $10 \mu \mathrm{m}$ we estimated from the ideal homogeneous case) and the corresponding attenuation never exceeds $-0.01 d B$. In such cases, Titan's atmosphere is totally transparent to microwaves and its effect should be totally neglected in the future processing of Cassini radar data.

- on the contrary, when we add in our simulation a rain layer in the last few 
kilometers, the attenuation reaches and rapidly exceeds the instrument sensitivity limit, due to the enhancement in size of the particles encountered (that could reach a few millimeters). A wave emerging from such a cloud layer could be so attenuated that the radar antenna wouldn't be able to detect a returned echo from Titan's surface. This could be a problem for the retrieval of Titan's surface images, as well as for altimetry measurements, and it should be taken into account when interpreting future data of the Cassini Radar experiment.

Simulation of the backscattered signal by Titan's surface covered by tholins also shows that a rather low return could be expected, even for rough surfaces. This could dramatically increase the possible attenuation role of Titan's atmosphere.

There is also a non-negligible risk for the Cassini radar instrument to detect a false signal coming from a reflective atmospheric layer, screening and flooding the surface signal, that could cause false interpretation of "surface" images. As the Cassini radar is a multipurpose instrument, a way to discriminate between possible atmospheric and surface echoes would be to combine altimetric and SAR data. It could then be possible to avoid false interpretation of "non-surfacic" signal, if both altimetric and SAR acquisition can be performed in the same short time period. The altimetry pulse shape could also be analyzed in order to detect an atmospheric effect and get unexpected information about Titan's lower atmosphere (rain occurrence and extension of cloud systems, size, density and velocity of the particles). In a flyby strategy which would maximize the coverage of Titan's surface, the radar will certainly not map the same region twice. In this case, using the altimetry data would be the only way to discriminate possible cloud layers from surface features. On the other hand, two 
flybys over the same area could give the opportunity to distinguish persistent features related to the surface from transient ones, which are likely to be due to atmospheric phenomena.

The new analysis scheme we propose for the Cassini radar measurements will be subject to further investigations. For this purpose, we shall improve our present simulation of the Cassini Radar instrument in order to model the behaviour of the pulse it will send towards Titan's surface (not only power attenuation, but also shape distortion). We shall also take into account the doppler shift in frequency of the signal sent and received by the orbiter, as could be produced by the relative motion of the atmospheric scatterers. In order to properly prepare for the analysis of future Cassini radar data, we also need for more accurate measurements of haze and rain properties (size, density and dielectric constant) as we showed the sensitivity of our calculations to these parameters. Rain droplet radius and condensation efficiency in the low atmosphere are in particular crucial parameters. Such information could also be retrieved from the combined interpretation of independent observations of Titan's atmosphere coming from the other instruments onboard the Cassini orbiter or Huygens probe, as well as results of future rain modeling.

\section{ACKNOWLEDGMENTS}

We sincerely thank PIOM's director, Jean-Paul Parneix, and LISA's director, François Raulin, who welcomed us in their laboratories and gave us the opportunity to instructively collaborate with some of their team members. We are also very grateful to Jonathan Braine who patiently checked the English language of the paper. This work was supported by the French Programme National de Planétologie of the Institut 
National des Sciences de l'Univers, CNRS.

\section{References}

Bohren, C.F., and D.R. Huffman 1983. Absorption and Scattering of Light by Small Particles, A Wiley-Interscience Publication.

Boudouris, G. 1971. Cavité électromagnétique, , Dunod, Paris édition.

Cabane, M., E. Chassefière, and G. Israël 1992. Formation and growth of photochemical aerosols in Titan's atmosphere. Icarus 96, 176-189.

Cabane, M., P. Rannou, E. Chassefière, and G. Israël 1993. Fractal aggregates in Titan's atmosphere. Planet. Space Sci. 41, 176-189.

Coll, P., D. Coscia, N. Smith, M.-C. Gazeau, S.I. Ramirez, G. Cernogora, G. Israël, and F. Raulin 1999a. Experimental laboratory simulation of Titan's atmosphere: aerosols and gas phase. Planet. Space Sci. 47, 1331-1340.

Coll, P., J.C. Guillemin, M.-C. Gazeau, and F. Raulin 1999b. Report and implications of the first observation of $C_{4} N_{2}$ in laboratory simulations of Titan's atmosphere. Planet. Space Sci. 47, 1433-1440.

Courtin, R., D. Gautier, and C.P. McKay 1995. Titan's thermal emission spectrum: reanalysis of the Voyager infrared measurements. Icarus 114, 144-162.

Coustenis, A., E. Lellouch, J.P. Maillard, and C.P. McKay 1995. Titan surface: Composition and variability from its near-infrared albedo. Icarus 118, 87-104. 
Coustenis, A., E. Lellouch, M. Combes, R. Wittemberg, C.P. McKay, and J.P. Maillard 1997. Titan's atmosphere and surface from infrared spectroscopy and imaging. In Astronomical and Biochemical Origins and the Search for Life in the Universe (C.B. Cosmovici, S. Bowyer, and D. Werthimer, Eds.), 277-234. Proceedings of IAU Colloquium 161.

Coustenis, A., B. Schmitt, R.K. Khanna, and F. Trotta 1999. Plausible condensates in Titan's stratosphere from Voyager infrared spectra. Planet. Space Sci. 47, 13051329.

Coustenis, A., E. Gendron, O. Lai, J.P. Véran, J. Woillez, M. Combes, L. Vapillon, T. Fusco, L. Mugnier, and P. Rannou 2001. Images of Titan at 1.3 and $1.6 \mu m$ with adaptative optics at the CFHT. Icarus 154, 501-515.

Danielson, R.E., J.J. Caldwell, and D.R. Larach 1973. An inversion in the atmosphere of Titan. Icarus 20, 437-446.

Dierking, W. 1999. Quantitative roughness characterisation of geological surfaces and implications for radar signature analysis. Proceedings of the IEEE on Geoscience and Remote Sensing 37, n.5, 2397-2412.

Elachi, C., E. Im, L.E. Roth, and C.L. Werner 1991. Cassini Titan radar mapper. Proceedings of the IEEE on Geoscience and Remote Sensing 79, n.6, 867-880.

Eshleman, Von R., G.F. Lindal, and G.L. Tyler 1983. Is Titan wet or dry? Science 221, 53-55.

Frère, C., F. Raulin, G. Israël, and M. Cabane 1990. Microphysical modeling of Titan's aerosols: application to the in situ analysis. Adv. Space Res. 10, 159-163. 
Fung, A.K., and H.J. Eom 1981. Multiple scattering and depolarization by a randomly rough Kirchhoff surface. Proceedings of the IEEE on Antennas Propagation AP-29, n.3, 463-471.

Gibbard, S.E., B. Macintosh, D. Gavel, C.E. Max, I. de Pater, A.M. Ghez, E.F. Young, and C.P. McKay 1999. Titan: high resolution speckle images from the Keck telescope. Icarus 139, 189-201.

Griffith, C.A., T. Owen, G.A. Miller, and T.R. Geballe 1998. Transient clouds in Titan's lower stratosphere. Nature 395, 575-578.

Griffith, C.A., J.L. Hall, and T.R. Geballe 2000. Detection of daily clouds on Titan. Science 290, 509-513.

Guez, L., and P. Bruston, F. Raulin, and C. Régnaut 1997. Importance of phase changes in Titan's lower atmosphere. Tools for the study of nucleation. Planet. Space Sci. 45, n.6, 611-625.

Hanel, B.A., and 15 colleagues 1981. Infrared observations of the Saturnian system from Voyager 1. Science 212, 192-200.

Hansen, J.E., and L.D. Travis 1974. Light scattering in planetary atmospheres. Space Sci. Rev. 16, 527-610.

Ishimaru, A. 1997. Scattering and absorption of a wave by a single particle. In Wave Propagation and Scattering in Random Media (Donald G. Dudley, Series Editor) pp. 9-40. Oxford University Press. 
Khanna, R.K., M.A. Perera-Jarmer, and M.J. Ospina 1987. Vibrational infrared and Raman spectra of dicyanoacetylene. Spectrochim. Acta, 43A, 421-425.

Khare, B.N., and C. Sagan 1973. Red clouds in reducing atmospheres. Icarus 20, $311-321$.

Khare, B.N., C. Sagan, E.T. Arakawa, F. Suits, T.A. Callcott, and M.W. Williams 1984. Optical constants of organic tholins produced in a simulated atmosphere: From soft X-ray to microwave frequencies. Icarus $\mathbf{6 0}, 127-137$.

Lara, L.M., E. Lellouch, J.J. López-Moreno, and R. Rodrigo 1996. Vertical distribution of Titan's atmospheric neutral constituents. J. Geophys. Res. 101, Issue E10, 2326123284 .

Lara, L.M., E. Lellouch, J.J. López-Moreno, and R. Rodrigo 1998. Erratum: Vertical distribution of Titan's atmospheric neutral constituents. J. Geophys. Res. 103, Issue E11, 25775-25776.

Lellouch, E., D.M. Hunten, G. Kockarts, and A. Coustenis 1990. Titan's thermospheric profile. Icarus 83, 308-324.

Lorenz, R.D. 1993a. The life, death and afterlife of a raindrop on Titan. Planet. Space Sci. 41, 647-655.

Lorenz,R.D. 1993b. The surface of Titan in the context of ESA's Huygens probe. ESA J. 17, 275-292.

Lorenz, R.D., and J.I. Lunine 1997. Titan's surface reviewed: the nature of bright and dark terrain. Planet. Space Sci. 45, 981-992. 
Lunine, J.I., D.J. Stevenson, and Y.L. Yung 1983. Ethane ocean on Titan. Science 222, 1229-1230.

McKay,C.P. 1996. Elemental composition, solubility, and optical properties of Titan's organic haze. Planet. Space Sci. 44, 741-747.

McKay, C.P., J.B. Pollack, and R. Courtin 1989. The thermal structure of Titan's atmosphere. Icarus 80, 23-53.

McKay, C.P., A. Coustenis, R.E. Samuelson, M.T. Lemmon, R.D. Lorenz, M. Cabane, P. Rannou, and P. Drossart 2001. Physical properties of the organic aerosols and clouds on Titan. Planet. Space Sci. 49, 79-99.

Muhleman, D.O., A.W. Grossman, B.J. Butler, and M.A. Slade 1990 . Radar reflectivity of Titan. Science 248, 975-980.

Podolak, M., and R.E. Danielson 1977. Axel dust on Saturn and Titan. Icarus 30, 479-492.

Podolak, M., and L.P. Giver 1979. An inhomogeneous scattering model of Titan's atmosphere. Icarus $\mathbf{3 7}, 361-376$.

Rages, K., and J.B. Pollack 1980. Titan aerosols: Optical properties and vertical distribution. Icarus 41, 119-130.

Rages, K., and J.B. Pollack 1983. Vertical distribution of scattering hazes in Titan's upper atmosphere. Icarus 55, 50-62. 
Rannou, P., M. Cabane, and E. Chassefière 1993. Growth of aerosols in Titan's atmosphere and related time scales: a stochastic approach. Geophys. Res. Lett. 20, 967-970.

Rannou, P., M. Cabane, E. Chassefière, R. Botet, C.P. McKay, and R. Courtin 1995. Titan's geometric albedo: role of the fractal structure of the aerosols. Icarus 118, $355-372$.

Sagan, C., and W.R. Thompson 1984. Production and condensation of organic gases in the atmosphere of Titan. Icarus 59, 133-161.

Samuelson, R.E., and L.A. Mayo 1997. Steady-state model for methane condensation in Titan's troposphere. Planet. Space Sci. 45, n.8, 949-958.

Sen, A.D., V.G. Anicich, and T. Arakelian 1992. Dielectric constant of liquid alkanes and hydrocarbon mixtures. J. Phys. D 25, 516-521.

Singh, S.P., and R.C. Miller 1979. Compressed-liquid dielectric constants and derived excess volumes for binary and ternary mixtures of $\mathrm{N}_{2}, \mathrm{Ar}, \mathrm{CH}_{4}$ and $\mathrm{C}_{2} \mathrm{H}_{6}$. J. Chem. Thermodynamics 11, 395-409.

Smith, B.A., and 25 colleagues 1981. Encounter with Saturn: Voyager 1 imaging science results. Science $\mathbf{2 1 2}$, 163-191.

Smith, B.A., and 28 colleagues 1982. A new look at the Saturn system: The Voyager 2 images. Science 215, 504-537.

Smith, P.H., M.T. Lemmon, R.D. Lorenz, L.A. Sromovsky, J.J. Caldwell, and M.D. Allsion 1996. Titan's surface, revealed by HST imaging. Icarus 119, 336-349. 
Thompson, W.D., and S.W. Squyres 1990. Titan and other icy satellites: Dielectric properties of constituent materials and implications for radar sounding. Icarus $\mathbf{8 6}$, $336-354$.

Tomasko, M.G. 1980. Preliminary results of polarimetry and photometry of Titan at large phase angles from Pioneer 11. J. Geophys. Res. 85A, 5937-5942.

Tomasko, M.G., and P.H. Smith 1982. Photometry and polarimetry of Titan: Pioneer 11 observations and their implications for aerosol properties. Icarus 51, 65-95.

Toon, O.B., R.P. Turco, and J.B. Pollack 1980. A physical model of Titan's clouds. Icarus 43, 260-282.

Toon, O.B., C.P. McKay, R. Courtin, and T.P. Ackerman 1988. Methane rain on Titan. Icarus 75, 255-284.

Toublanc, D. , J.P. Parisot, J. Brillet, D. Gautier, F. Raulin, and C.P. McKay 1995. Photochemical modeling of Titan's atmosphere. Icarus 113, 2-26.

Ulaby, F.T., R.K. Moore, and A.K. Fung 1982. Microwave Remote Sensing: Active and Passive, Artech House, Noorwood MA.

Ulamec, S., J. Badoz, and J.P. Lebreton 1992. Dielectric constant measurements in simulated Titan ocean liquids. In ESA SP-338 401-405. Proceedings Symposium on Titan.

Veverka, J. 1973. Titan: Polarimetric evidence for an optically thick atmosphere. Icarus $\mathbf{1 8}, 657-660$. 
Yung, Y.L., M. Allen, and J.P. Pinto 1984. Photochemistry of the atmosphere of Titan: Comparison between model and observations. ApJS 55, 465-506.

Zellner, B. 1973. The polarization of Titan. Icarus 18, 661-664. 
Table 1: Methane rain properties retrieved from modeling by Toon et al. (1988) and Courtin et al. (1995).

\begin{tabular}{ll}
\hline Physical property & Value \\
\hline Cloud extension & $20 \mathrm{~km}$ \\
Altitude of cloud top & $z=30-40 \mathrm{~km}$ \\
Mean raindrop radius & between $50 \mu \mathrm{m}$ and $3 \mathrm{~mm}$ (Toon only) \\
Raindrop density & between 1 and $3500 \mathrm{~m}^{-3}$ (Toon only) \\
Optical thickness & $\leq 2$ (far-infrared) \\
\hline
\end{tabular}


Table 2: Set of samples supplied by simulations at LISA

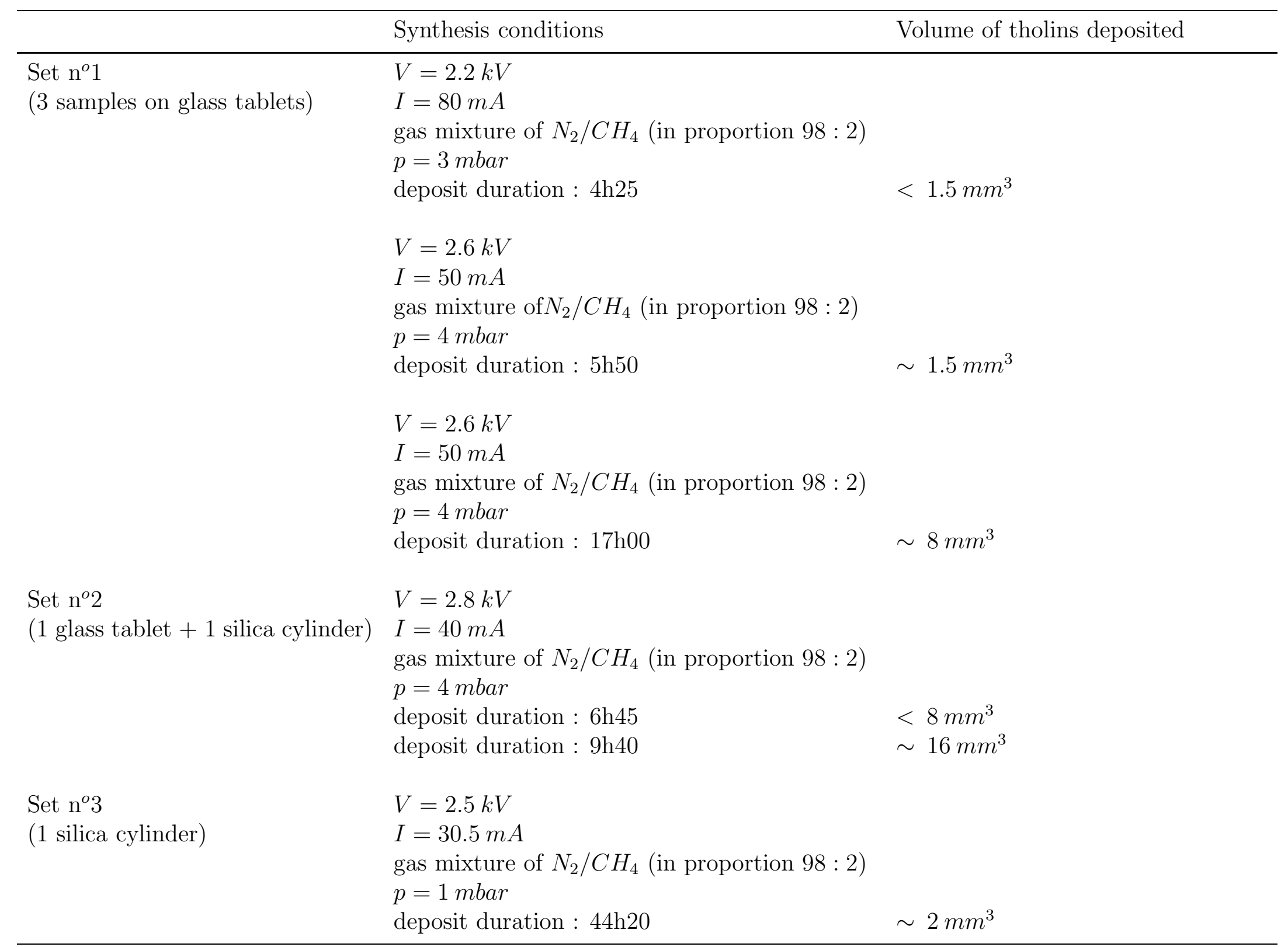


Table 3: Tholin dielectric constants measured in resonant cavities.

\begin{tabular}{lll}
\hline & Cavity used & Dielectric constant \\
\hline Set $\mathrm{n}^{\circ} 1$ & $2.45 \mathrm{GHz}$ & $\varepsilon_{r}=2.26-j 0.12$ \\
Set $\mathrm{n}^{\circ} 2$ & 2.45 and $10 \mathrm{GHz}$ & $\varepsilon_{r}=2.2-j 0.002$ \\
Set $\mathrm{n}^{\circ} 3$ & $10 \mathrm{GHz}$ & $\varepsilon_{r}=2.03-j 0.022$ \\
\hline
\end{tabular}


Table 4: Microwave dielectric constants of some major materials suspected to compose Titan's atmosphere and surface.

\begin{tabular}{llll}
\hline Species & Dielectric constant & Frequency range of validity & Source \\
\hline Pure liquid $\mathrm{CH}_{4}(94 \mathrm{~K})$ & $\varepsilon_{r}=1.7-j 1.5 \times 10^{-2}$ & hundreds of MHz & Thompson and Squyres (1990) \\
$\begin{array}{l}\text { Perfectly mixed } \\
\mathrm{CH}_{4}-\mathrm{C}_{2} \mathrm{H}_{6} \text { liquid } \\
(\text { around } 100 \mathrm{~K})\end{array}$ & $\varepsilon_{r}=1.8-j 2 \times 10^{-3}$ & $\mathrm{GHz}$ & Singh $(1979)$ \\
& & & Sen et al. $(1992)$ \\
$\begin{array}{l}\text { Pure } \mathrm{H}_{2} \mathrm{O} \text { ice } \\
\text { (between } 90 \text { and } 273 \mathrm{~K})\end{array}$ & $\varepsilon^{\prime} \sim 3.1$ & $\sim 10 \mathrm{GHz}$ & Ulaby et al. $(1982)$ \\
$\begin{array}{l}\text { Pure } \mathrm{CH}_{4}-\mathrm{C}_{2} \mathrm{H}_{6} \\
\text { ice }(\text { around } 90 \mathrm{~K})\end{array}$ & $\varepsilon^{\prime} \sim 2-2.4$ & $\sim 10 \mathrm{GHz}$ & Thompson and Squyres $(1990)$ \\
\hline
\end{tabular}


Table 5: Summary of the atmospheric models for Titan used in our simulations.

\begin{tabular}{|c|c|c|}
\hline Scenario label & Description & Physical properties \\
\hline Dry atmospheres & only aerosols & \\
\hline $\mathrm{A}$ & $\begin{array}{l}\text { Homogeneous multi-layer model } \\
\text { (with } 0.1 \mu m \text {-radius particles in the main haze layer) }\end{array}$ & $\begin{array}{l}\text { Tholin dielectric constant } \\
\varepsilon^{\prime}=2.2 \pm 0.1 \\
\varepsilon^{\prime \prime}=0.05 \pm 0.05\end{array}$ \\
\hline $\mathrm{B}$ & $\begin{array}{l}\text { Homogeneous multi-layer model } \\
\text { (with } 0.5 \mu \mathrm{m} \text {-radius particles in the main haze layer) }\end{array}$ & $i d e m$ \\
\hline $\mathrm{C}$ & $\begin{array}{l}\text { Inhomogeneous model taken from McKay et al. (1989) } \\
\text { (see Fig. 1-(a)) }\end{array}$ & $i d e m$ \\
\hline $\mathrm{D}$ & $\begin{array}{l}\text { Inhomogeneous model taken from Cabane et al. (1992) } \\
\text { (see Fig. 1-(a)) }\end{array}$ & $i d e m$ \\
\hline Wet atmospheres & aerosols + condensation droplets & \\
\hline $\mathrm{E}$ & $\begin{array}{l}\text { Inhomogeneous model taken from Frère et al. }(1990) \\
\text { including condensation at low alitude (below } 100 \mathrm{~km} \text { ) } \\
\text { (see Fig. } 1-(\mathrm{a}) \text { ) }\end{array}$ & $\begin{array}{l}\text { Droplet dielectric constant } \\
\text { (mixed hydrocarbons) } \\
\varepsilon_{r}=1.8-j 2 \times 10^{-3}\end{array}$ \\
\hline $\mathrm{A} \sharp$ & $\begin{array}{l}\text { Homogeneous multi-layers model } \mathrm{A} \\
+ \text { methane rain layer between } 30 \text { and } 10 \mathrm{~km} \text { altitude }\end{array}$ & $\begin{array}{l}\text { Pure } \mathrm{CH}_{4} \text { rain layer } \\
\text { (nominal case) } \\
\text { extension: } 10-30 \mathrm{~km} \\
\text { radius: } 2 \mathrm{~mm} \\
f=10^{-4} \% \\
\varepsilon_{r}=1.7-j 1.5 \times 10^{-2}\end{array}$ \\
\hline $\mathrm{B} \sharp$ & $\begin{array}{l}\text { Homogeneous multi-layers model } \mathrm{B} \\
+ \text { methane rain layer between } 30 \text { and } 10 \mathrm{~km} \text { altitude }\end{array}$ & $i d e m$ \\
\hline $\mathrm{C} \sharp$ & $\begin{array}{l}\text { Inhomogeneous model } \mathrm{C} \\
+ \text { methane rain layer between } 30 \text { and } 10 \mathrm{~km} \text { altitude }\end{array}$ & $i d e m$ \\
\hline $\begin{array}{l}\mathrm{D} \sharp \\
\square\end{array}$ & $\begin{array}{l}\text { Inhomogeneous } \mathrm{D} \\
+ \text { methane rain layer between } 30 \text { and } 10 \mathrm{~km} \text { altitude }\end{array}$ & $i d e m$ \\
\hline
\end{tabular}




\section{FIGURE CAPTIONS}

Figure 1. (a) Inhomogeneous models of Titan's aerosol distribution inferred from microphysical calculations : (1) McKay et al. (1989), (2) Frère et al. (1990), and (3) Cabane et al. (1992). (b) Schematic representation of differential condensation processes occurring in the 100 last kilometers of Titan's atmosphere as modeled by Frère et al. (1990). Differential condensation of hydrocarbons and nitriles control the size, density and chemical composition of the aerosol below $100 \mathrm{~km}$. Aerosols are then of increasing size with decreasing altitude, reaching a maximum radius of $\sim 900 \mu \mathrm{m}$ around $10 \mathrm{~km}$ altitude. Below this altitude, sublimation of liquids surrounding the aerosol leads to a reduction of the particle size until hypothetical complete sublimation occurs 2-3 km above the ground.

Figure 2. Geometry and description of the multi-layer model we used for atmospheric transmission computation.

Figure 3. (a): Attenuation versus particle radius and density for a $500 \mathrm{~km}$ thick homogeneous atmosphere with $\varepsilon_{r}=2.2-j 0.05$; (b): 12.5 dB-threshold versus radius and density of dielectric spheres $\left(\varepsilon_{r}=2.2-j 0.05\right)$ for a $500 \mathrm{~km}$ thick homogeneous medium. The grayed region represents atmosphere models for which the radar is unable to see the surface of Titan.

Figure 4. Attenuation caused by heterogeneous models (aerosol only and aerosol+condensation 
droplets). The description and properties of each scenario symbolized by letters in this figure can be found in Table 5. The minimum values for attenuation were calculated with $\varepsilon^{\prime}=2.1$ and $\varepsilon^{\prime \prime}=0$, and the maximum values with $\varepsilon^{\prime}=2.1$ and $\varepsilon^{\prime \prime}=0.1$. The mean attenuation was calculated with a value of $\varepsilon_{r}=2.2-j 0.05$ contained within the two attenuation extrema symbolized by the errorbars. The comparison between "dry" models and "wet" ones emphasizes the drastic increase in attenuation due to rain occurrence. Errorbars are too small to be seen in the "wet" model case, due to the fact that aerosol attenuation - the only source of incertitude here- become negligible compared to the rain effect. The solid horizontal line shows the sensitivity threshold at $-12.5 \mathrm{~dB}$, and the dotted line represents the $-4 \mathrm{~dB}$ threshold.

Figure 5. (a): Attenuation for heterogeneous models $\mathbf{A} \sharp, \mathbf{B} \sharp, \mathbf{C} \sharp$, and $\mathbf{D} \sharp$ with increasing droplet radius from no rain $(0 \mathrm{~mm})$ to the limit of $4.5 \mathrm{~mm}$ imposed by Lorenz (1993); (b): Attenuation for models $\mathbf{A} \sharp, \mathbf{B} \sharp, \mathbf{C} \sharp$, and $\mathbf{D} \sharp$ with increasing condensation efficiency on aerosols (factor $f$ ) varying between our nominal case $\left(10^{-4 \%}\right.$ ), in agreement with Toon et al. (1988), and 0.1\%. Errorbars on attenuation values due to uncertainties in the dielectric constant of tholin become insignificant beyond a certain value of $r(2 \mathrm{~mm})$ and are totally hidden by attenuation due to rain as soon as $f$ is higher than $10^{-4 \%}$. For (a) and (b), the dielectric constant of tholins was taken from the value we experimentally measured: $\varepsilon_{r}=2.2 \pm 0.1-j 0.05 \pm 0.05$. The solid horizontal line shows the $-12.5 \mathrm{~dB}$ sensitivity threshold and the dotted line the $-4 \mathrm{~dB}$ threshold. 
Figure 6. Geometry of the single layer scattering problem.

Figure 7. Compared radar backscattered power for a relatively smooth surface $(\sigma=$ $0.5 \mathrm{~cm}$ and $L=25 \mathrm{~cm}, \mathrm{PO}$ model $)$ and a rough surface $(\sigma=7 \mathrm{~cm}$ and $L=10 \mathrm{~cm}, \mathrm{GO}$ model $)$ covered by tholins $\left(\varepsilon_{r}=2.2-j 0.05\right)$, water ice $\left(\varepsilon_{r}=3.1-j 0.001\right)$ or liquid methane $\left(\varepsilon_{r}=1.7-j 0.015\right)$. The solid horizontal line shows the sensitivity threshold at $-25 \mathrm{~dB}$. 


\section{Radii \\ Densities}
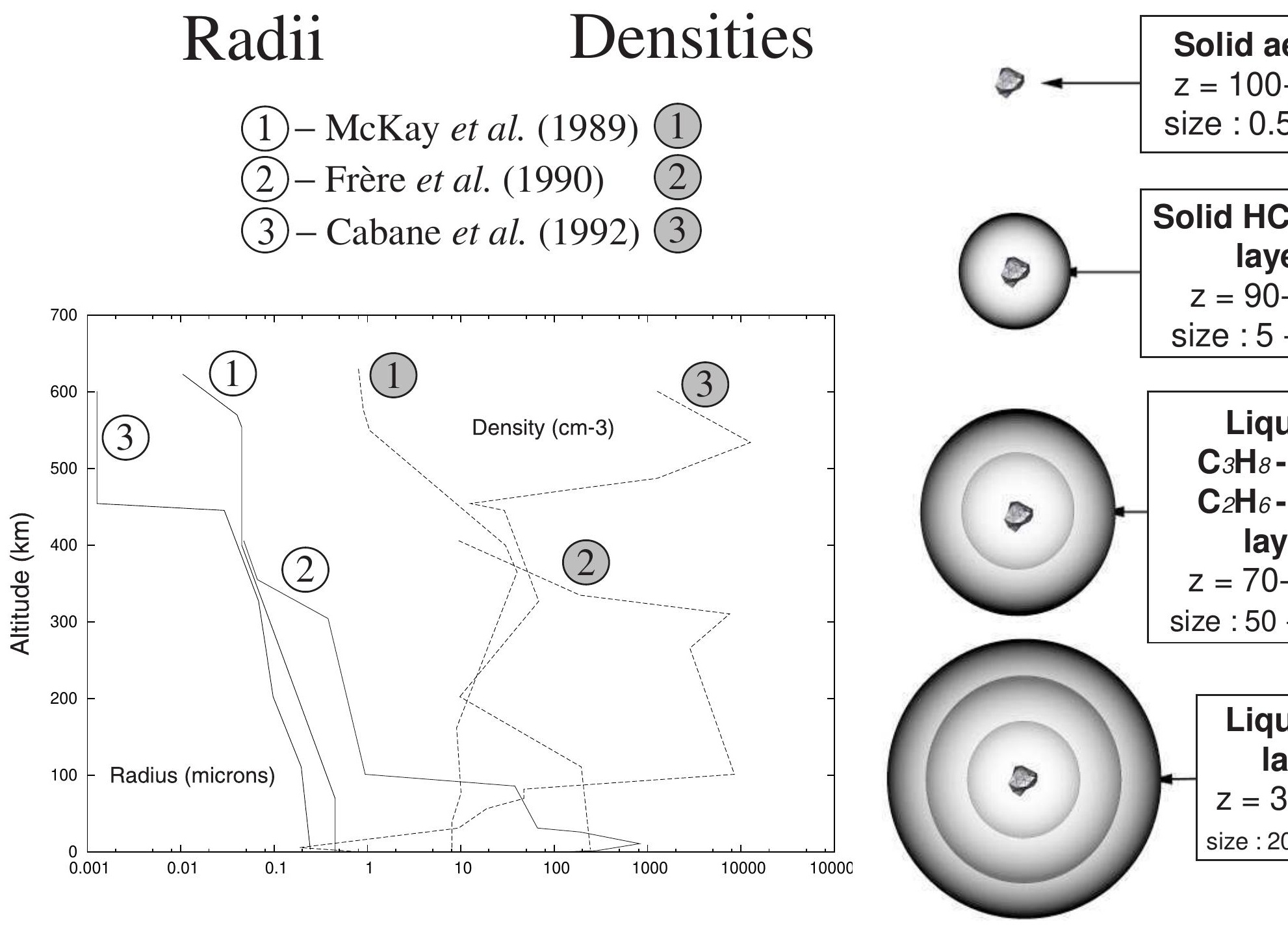

a)

b)

Figure 1: Rodriguez et al., Impact of Titan's aerosols on Cassini/Radar experiment 
a)

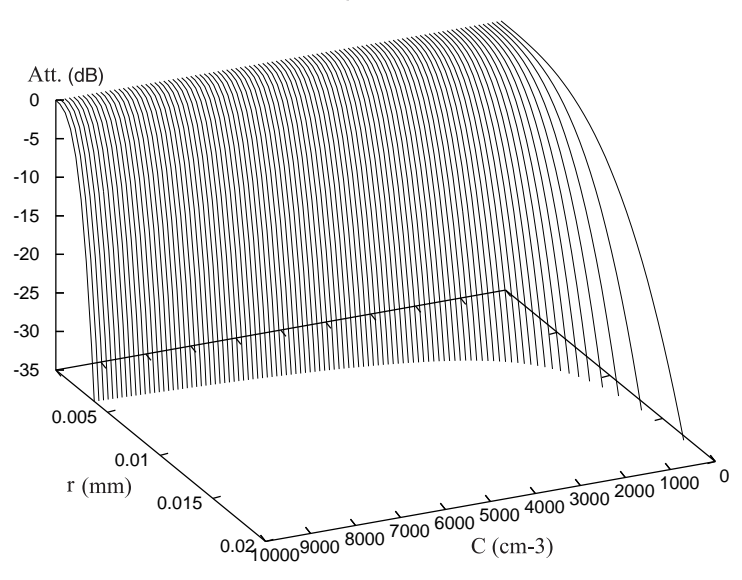

b)

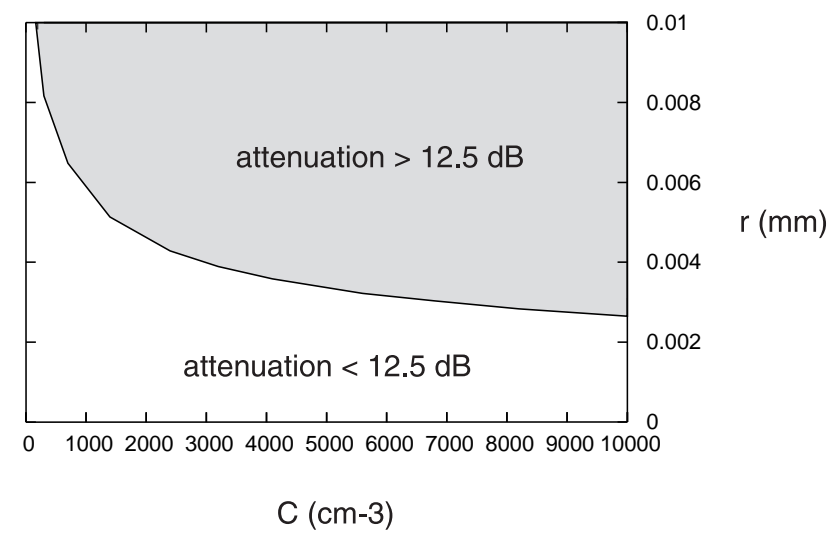

Figure 3: Rodriguez et al., Impact of Titan's aerosols on Cassini/Radar experiment

Figure 3: Rodriguez et al., Impact of Titan's aerosols on Cassini/Radar experiment 


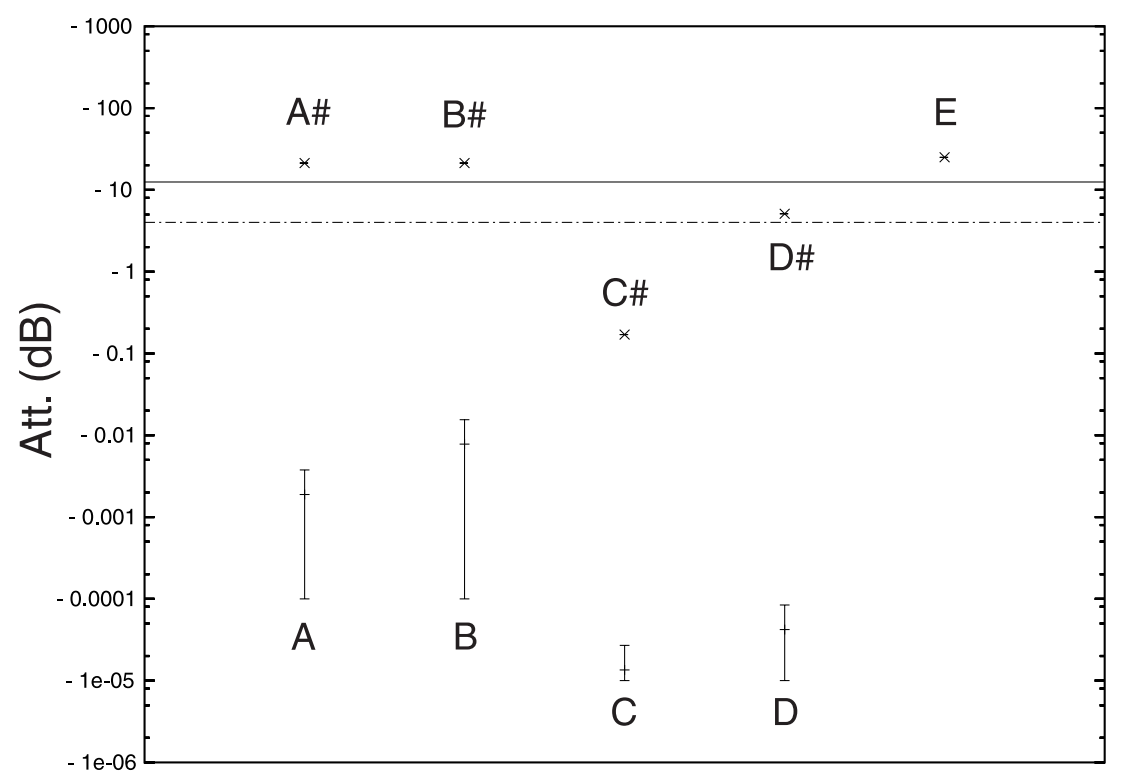

Figure 4: Rodriguez et al., Impact of Titan's aerosols on Cassini/Radar experiment

Figure 4: Rodriguez et al., Impact of Titan's aerosols on Cassini/Radar experiment 

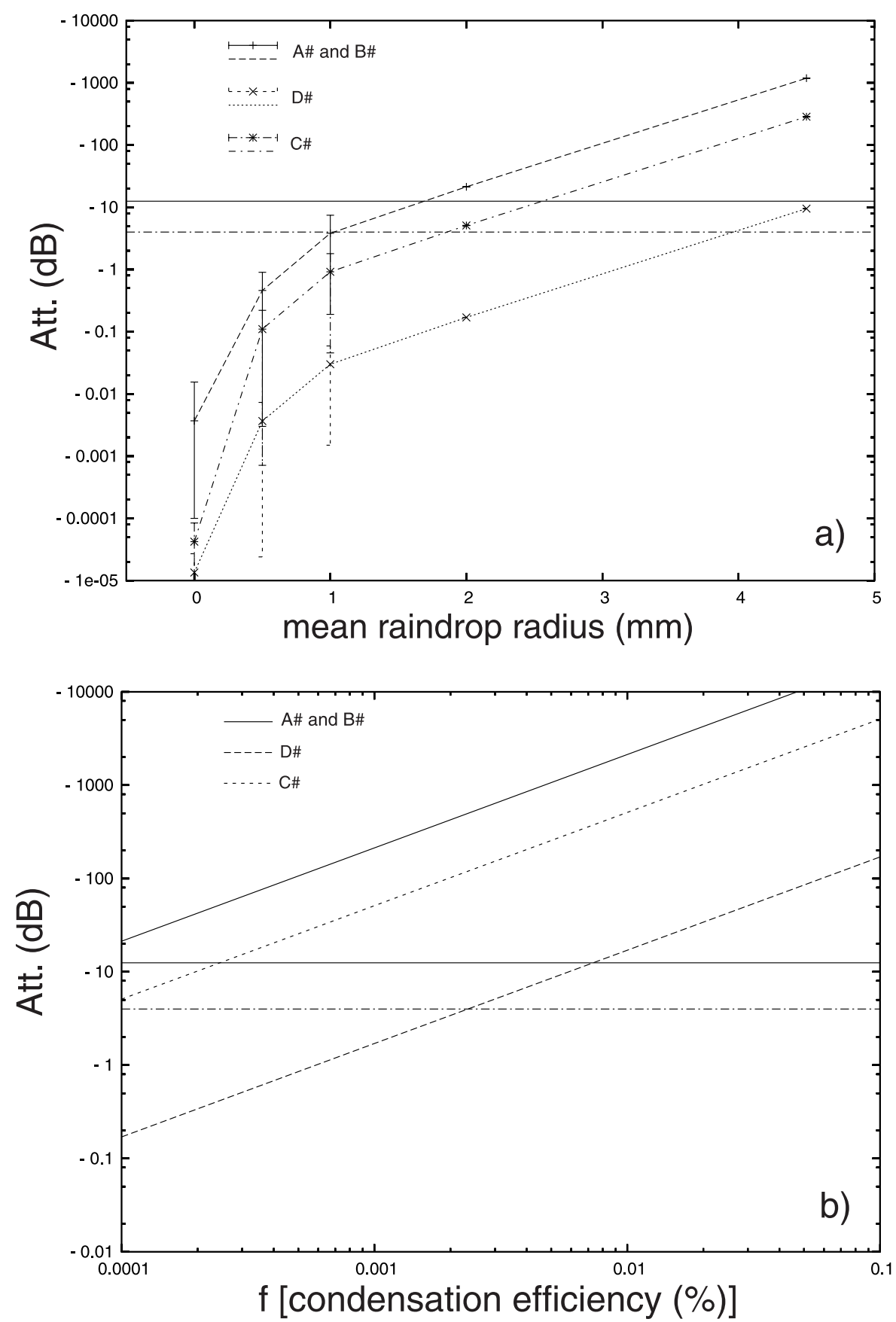

Figure 5: Rodriguez et al., Impact of Titan's aerosols on Cassini/Radar experiment

Figure 5: Rodriguez et al., Impact of Titan's aerosols on Cassini/Radar experiment 


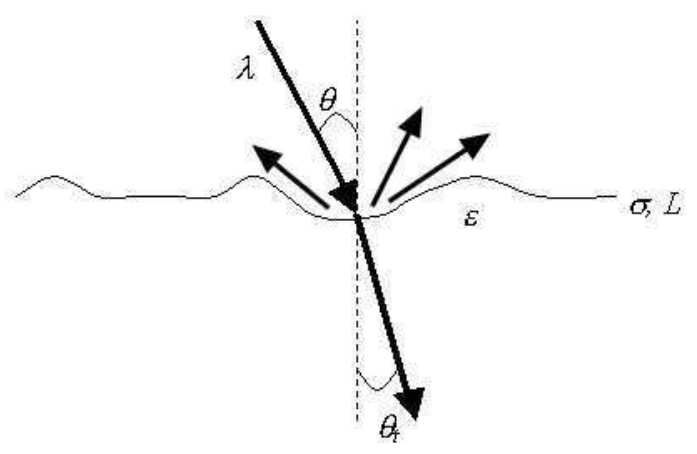

Figure 6: Rodriguez et al., Impact of Titan's aerosols on Cassini/Radar experiment 


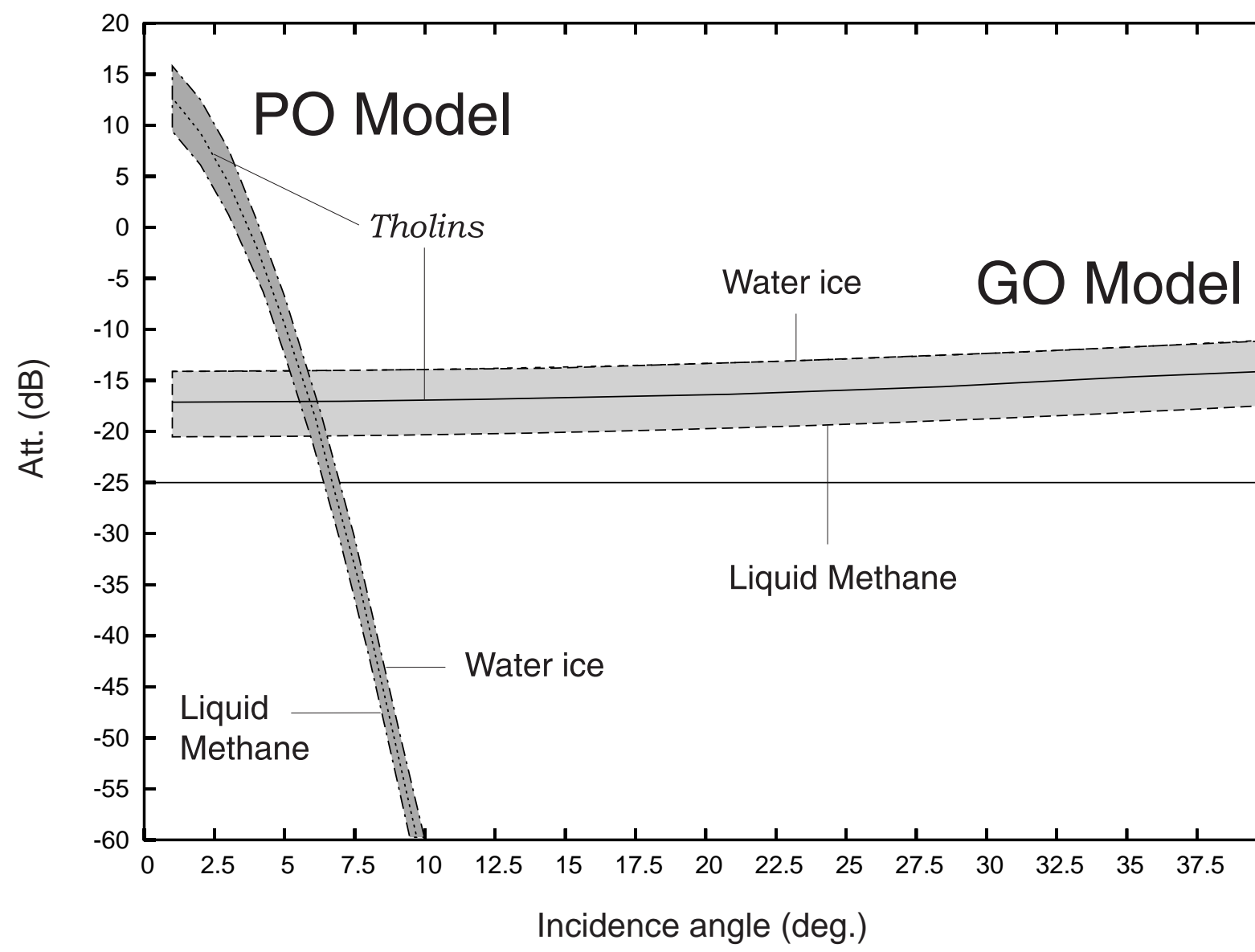

Figure 7: Rodriguez et al., Impact of Titan's aerosols on Cassini/Radar experiment 